\title{
Context Factors and the Performance of Mobile Individuals in Research Teams
}

\section{Chiara Franzoni, Giuseppe Scellato and Paula Stephan}

Politecnico di Milano; Politecnico di Torino and Collegio Carlo Alberto; Georgia State University

ABSTRACT We use survey data for 4336 scientific teams, located in 16 countries, where all members were working within a single lab, to test three context factors that potentially affect the capability of internationally mobile individuals to enhance the innovation performance of their research units. We formulate hypotheses on context factors rooted in the knowledge recombination and learning-by hiring theories. The results show that three context factors are positively associated with international mobility and the performance of the research units: the degree to which knowledge in the relevant subfield of science is geographically concentrated, the creative intent of the activities performed and the decision power of the mobile individual.

Keywords: creativity, ethnicity, mobility, research teams, team performance

\section{INTRODUGTION}

Mobility of highly-qualified workers has been identified as a critical mechanism by which organizations acquire distant knowledge, learn new routines and spur creativity, change, and ultimately innovation (Dokko and Rosenkopf, 2010; Mawdsley and Somaya, 2016; Palomeras and Melero, 2010; Rosenkopf and Almeida, 2003; Singh and Agrawal, 2011; Slavova et al., 2016; Song et al., 2003). International movers are one special component of highly-qualified mobile workers, and one that has received comparatively little attention from management scholars, despite their growing importance in intellectually-challenging professions. According to the OECD-UNDESA (2013) report, during the first decade of the 2000s, the global mobility of the high-skilled (e.g., individuals with tertiary-education) increased by about 70 per cent, sufficient to make the rate of the tertiary-educated who migrate from their origin country surpass the total emigration rate in virtually all countries. ${ }^{[1]}$ Internationally-mobile workers in the USA were found to disproportionately

Address for reprints: Giuseppe Scellato, Department of Management and Production Engineering, Politecnico di Torino and Collegio Carlo Alberto, Corso Duca degli Abruzzi 24, Torino, 10129, Italy (giuseppe.scellato@polito.it); Chiara Franzoni, School of Management, Politecnico di Milano, Piazza Leonardo da Vinci 32, Milan, 20133, Italy (chiara.franzoni@polimi.it)

This is the peer reviewed version of the following article: Franzoni C., Scellato G., Stephan P., "Context Factors and the Performance of Mobile Individuals in Research Teams", Journal of Management Studies, 2018, 55:1, 27-59, which has been published in final form at https://doi.org/10.1111/joms.12279.

This article may be used for non-commercial purposes in accordance with Wiley Terms and Conditions for Use of SelfArchived Versions 
account for patented inventions, including higher-quality patents (No and Walsh, 2010) and be more likely to become entrepreneurs (Hsu et al., 2007; Hunt, 2011).

The hiring of internationally-mobile professionals creates both opportunities and challenges in the management of human capital within teams and companies. The literature on learning-by-hiring has stressed the relevance of the human and relational capital mobilized by new hires (Mawdsley and Somaya, 2016). In the context of research and innovation, international hires are seen as especially important for transferring knowledge and skills that are highly specialized, fragmented or tacit (Herstad et al., 2015) and cannot quickly be assimilated through other channels. To quote the physicist J. Robert Oppenheimer, 'The best way to send information is to wrap it up in a person' ${ }^{[2]}$ In theory, mobile individuals can make a positive contribution, by drawing on the knowledge acquired at their prior location (Dokko et al., 2009; Jaffe et al., 1993; Kogut and Zander, 1992), transferring ideas, and leading to greater absorptive capacity and learning within the receiving firms (Agrawal et al., 2006; Almeida and Kogut, 1999; Singh and Agrawal, 2011; Song et al., 2003). They are also facilitators of relationships because they can intermediate connections with collaborators and specialists known in prior locations, providing more indirect access to distant knowledge, in addition to the knowledge they supply (Breschi and Lissoni, 2009; Miguélez and Moreno, 2013; Scellato et al., 2015; Singh, 2005).

The direct and indirect knowledge brought by international movers is deployed to its best creative potential when used in combination with other sources of knowledge (Katila and Ahuja, 2002). The remixing of knowledge from local and distant sources creates opportunities to hybridize ideas, adopt cognitive maps, logics, specialized routines, methodologies, and solutions used in prior settings but new in the organization of destination (Dokko et al., 2009; Fleming, 2001; Hargadon and Sutton, 1997; Katila and Ahuja, 2002). These in turn help in overcoming the routines and traps of perpetuating familiar endeavours (Ahuja and Lampert, 2001; Rosenkopf and Almeida, 2003; Rosenkopf and Nerkar, 2001).

Empirical and conceptual understanding of the implications and caveats of international mobility are lacking in at least three respects. First, although knowledge flows have been documented in prior work, relatively few studies have tried to document the extent to which these translate to potentially higher performance, such as more or higher quality innovations. Second, although a bourgeoning literature has looked at inter-organizational mobility, few works have looked at international mobility. This is disappointing, given the growing importance of internationally-mobile human capital. Third, although sparse, prior work that has investigated the innovative performance of internationally-mobile individuals suggests that it is sometimes, but not always, associated with superior performance in creative tasks (for a review see Kerr, 2013 and Franzoni et al., 2014). Nonetheless, these analyses have largely overlooked context factors which likely affect conditions under which mobile individuals operate and thus perform. The capability of internationally-mobile workers to really make a difference at the new location may in fact be affected by a number of context factors that frame the conditions for the actual usage of the human and relational capital of mobile individuals.

This paper contributes to these three areas open to investigation, studying conceptually and empirically the correlation between internationally mobile individuals in teams 
and innovation. We focus on teams of scientists that work in the same lab or unit. This choice of setting offers several advantages, the most salient of which are: large portability of skills, ${ }^{[3]}$ a set of tasks clearly oriented to innovation, and relatively standard ways to measure output characteristics and performances. It is drawn on recent works which focus on scientific research as a setting for studying international mobility (Franzoni et al., 2014; Freeman and Huang, 2015; Ganguli, 2015; Slavova et al., 2016) as well as work that conceptualizes science in a knowledge recombination framework (Fleming and Sorenson, 2004; Wang et al., 2016). We use an original sample of 4336 surveyed scientists located in 16 countries conducting research in the four disciplines of biology, chemistry, earth and environmental sciences and materials science. The dataset provides us with comprehensive information on the subject of our investigation, including country of origin, instances of international mobility, and various kinds of context factors observed for each individual in the sample.

Drawing from the literature on inter-organizational mobility, we disentangle three families of context factors that likely contribute to explaining the correlation between international mobility and performance: i) the relative attributes of knowledge at the origin and destination, ii) the environmental conditions under which the work is carried out and iii) the attributes of the individual (Mawdsley and Somaya, 2016). Mirroring this conceptualization, in this paper we focus on three context factors which we choose because of their particular salience in the setting of internationally mobile scientists. First, the degree to which specialty knowledge is concentrated in a few geographic areas is one salient attribute that characterizes the respective position of the origin and destination settings and one that is characteristic of scientific competition (Stephan et al., 2016). Knowledge concentrates under the pressure of some agglomeration forces, like tacitness, inability to codify or the need of complementary skills that prevents diffusion, making the mobility of scientists a critical engine of transfer (Maliranta et al., 2009). Consequently, internationally mobile scientists should be more of a plus when agglomeration forces are strong. Second, the goals and tasks that mobile workers are called upon to perform are salient environmental conditions that affect the degree to which the mobilized resources may or may not be used (Song et al., 2003). When the organization strives to accomplish activities that are novel and unfamiliar, external input and knowledge recombination are more likely to be necessary and sought, compared to when a team engages simply in familiar activities. Third, the level of decision power that the mobile scientist enjoys at the destination is a salient attribute in the setting of science teams, which directly affects the level of knowledge that is drawn upon and its recombination with the knowledge of other members of the unit.

Here we distinguish scientific teams whose corresponding author is an internationally mobile scientist (hereafter: mobile-scientist team) from teams whose corresponding author is a non-mobile scientist (hereafter: non-mobile-scientist team) and compare the scientific achievements of the teams in light of the three context factors. We find all three factors to be associated with a positive performance differential for mobile-scientist teams.

The results persist using alternative measures of relevant variables as well as the inclusion of numerous individual and institution-level controls. Despite the robustness checks, the possibility of reverse-causality remains and we are cautious in suggesting that it is context that makes the mobile individuals more or less productive rather than mobile 
individuals being more likely to be employed in specific contexts. The results nonetheless provide important insights to the literature on knowledge recombination and highly qualified mobile workers and are relevant for the practice of managing the increasingly internationally-mobile human resources in innovative organizations.

The rest of the paper is organized as follows. Section 2 explains science lab organizations as the setting of our analysis. Section 3 reviews the literature on learning-by-hiring and integrates it with the nascent literature of international mobility and performance. It further introduces context factors and builds three hypotheses for testing. Section 4 describes the dataset and methods. Section 5 comments on the findings and the implications for scholars and practitioners and discusses limitations.

\section{THE CONTEXT OF THE STUDY: SGIENTIFIC LABS AND TEAMS}

Scientific research in most fields is organized and conducted in a laboratory setting. The lab is generally overseen by a principal investigator - what one researcher described as 'God in his realm' (Shapin, 2008). The parent institution, usually a research university or a public research organization, provides the principal investigator with lab space, equipment, and some funds for conducting research. In exchange, the principal investigator is usually responsible for raising additional funds, generally through the writing of grants, hiring (and firing) junior researchers - especially graduate students and postdoctoral researchers - and selecting and overseeing the research agenda of the lab. The principal investigator rarely spends time at the bench. Instead, research in the lab is generally conducted by a team which is selected by the principal investigator. In some labs the team constitutes all members of the lab; in other labs, multiple, sometime overlapping, teams conduct research simultaneously. Teams typically are organized in a semispecialized way, in which individuals perform a set of relatively complex tasks, such as the creation of a genetically modified mouse, the purifying of a protein, or running a complex piece of equipment.

Teams routinely meet with the principal investigator to discuss results and map out the next steps in the research. First drafts of articles based on team research are often written by the junior member of the team who played a key role in the research; the final draft is usually edited extensively by the principal investigator. The principal investigator therefore occupies a position that requires receiving, overseeing, interpreting and synthesizing a vast amount of information coming from the activities performed by members of the team as well as making critical decisions that affect the direction and productivity of the lab (Radner, 1992; Turner and Makhija, 2012).

\section{INTERNATIONAL MOBILITY, INNOVATION AND PERFORMANCE}

The theory of knowledge recombination conceptualizes innovation as a combinatorial process in which ideas and knowledge exist as pieces of information that have a practical role in a given technological domain, setting or industry (Fleming, 2001; Hargadon, 1998; Hargadon and Sutton, 1997; Kogut and Zander, 1992). Innovation may emerge as the result of experimenting with new combinations of knowledge, by searching, importing and using unfamiliar components or by trying to reconfigure known 
components into different technological domains, settings or industries (Fleming and Sorenson, 2004; Strumsky and Lobo, 2015).

The mobility of individuals has a special significance in this literature because the process of knowledge recombination is seen as having a natural tendency to be incremental and primarily driven by local search. Moreover, because of the bounded rationality of individuals (March and Simon, 1958), the limited absorptive capacity of organizations (Cohen and Levinthal, 1990; Volberda et al., 2010), and routines (Nelson and Winter, 1985) that constrain the level and depth of information processing (Ahuja and Lampert, 2001; Dokko et al., 2009), the search process of organizations tends to be limited to solutions that are either already known, readily-available, or easily understandable by team members (Dokko et al., 2009; Rosenkopf and Almeida, 2003; Stuart and Podolny, 1996). Furthermore, a large share of knowledge is uncodified and resides tacitly in the minds of qualified individuals (Nelson and Winter, 1985), such that it cannot be acquired except by working in close proximity with those who own it (Singh and Agrawal, 2011; Stephan, 1996). Nonetheless, tacit knowledge is necessary in addressing many hard-to-tackle or front-end science problems (Polanyi, 1962), which consequently remain accessible only to a few specialized individuals or groups.

Learning-by-hiring is one possible way to overcome these difficulties and expand the organization's capability to scan more problems and find more distant solutions (Kogut and Zander, 1992; Palomeras and Melero, 2010; Rosenkopf and Almeida, 2003; Singh and Agrawal, 2011; Slavova et al., 2016; Song et al., 2003). New hires can ideally bring technical knowledge, portfolios of prior experiences and heuristics useful in framing and analysing problems, as well as organizational capabilities, routines and tacit mental models (Polanyi, 1962). Whereas new hires provide the fuel for exploration, it is the recombination of their knowledge with local knowledge that ignites creative processes (Ahuja and Lampert, 2001; Dokko et al., 2009; Hargadon and Sutton, 1997; Katila and Ahuja, 2002). This is especially true in the context of scientific knowledge, because scientists often own highly fragmented and specialized competencies (Jones, 2009), and because epistemologies are socially-constructed (Kealey and Ricketts, 2014), such that performance depends quite substantially on the matching and collaboration with peers (Azoulay et al., 2010; Jones, 2009). For example, a problem that defies a solution if framed under a certain conceptualization or mental model can be addressed successfully when analysed with a different conceptualization or mental model.

The existence of knowledge flows associated with instances of mobility has been observed in studies of mobile inventors that used patent citations and patent classes to measure flows and the variety of knowledge associated with mobility (Agrawal et al., 2006; Marx et al., 2009; Rosenkopf and Almeida, 2003; Singh and Agrawal, 2011; Tzabbar, 2009). The methods relied upon in these studies, however, are unsuitable for investigating whether or not mobility-enabled knowledge recombination ultimately translates into superior innovation performance of the organizations in which the mobile person works. Few studies try to address this question, partly because of problems in finding good measures of innovative performance.

The few studies of inter-organizational mobility that have looked at performance are divided among those that report a direct negative performance effect for the firm (Hamori and Koyuncu, 2015; Maliranta et al., 2009), a negative performance effect for 
both the firm and the worker (Groysberg et al., 2008), or a positive but indirect effect of new hires on the productivity of colleagues (Slavova et al., 2016).

Among the studies of international mobility of high-skilled professionals, a few have focused on the correlation between mobility and performance, measuring innovation with scientific publications. Their findings are quite mixed. Stephan and Levin (2001) find evidence that foreign-born scientists outperform natives in the number of exceptional contributions including highly-cited papers, and election to prestigious societies. Franzoni et al. (2014) find that foreign-born scientists outperform natives with no international experience, after addressing selection into treatment with instrumental variables. Gruber, Haroff and Hoisl (2012), studied inter-firm mobility of inventors and its correlation with the breadth of technological recombination observable in patent classes. They find, among other results, that patents of mobile inventors are of broader technological breadth than those of the non-mobile inventors. No and Walsh (2010) find that US patents from foreign inventors are more cited than those of domestic US inventors.

Conversely, two independent studies comprising US and UK scientists do not find significant performance differentials across movers and non-movers (Hunter et al., 2009; Lawson et al. 2015). Kerr and colleagues (Kerr and Lincoln, 2010; Kerr et al., 2013) use stochastic name matching to differentiate immigrants from non-immigrants and find no evidence of performance differentials (including patent citations and patent originality) in a large sample of US inventors. Empirical comparisons in this respect are typically complicated by the fact that immigrants tend to have higher educational attainments than natives and to be hired in positions for which they are overqualified. Hunt (2011) finds that it is the educational edge, and not knowledge recombination that largely explains the performance differential. She finds, however, that US immigrants are more likely to found successful high-tech start-ups (with more than 10 employees) than are US natives. Liu and colleagues (2010) find that start-ups funded by Chinese entrepreneurs who had a former experience abroad are more inventive (measured by number of patents filed) than Chinese counterparts whose founder did not have prior international experience.

\section{Context Factors in Knowledge Recombination}

The results of empirical research concerning the relationship between international mobility and performance are thus inconclusive. A possible explanation for these mixed findings relates to the fact that, while mobility provides a likely condition to promote knowledge recombination, in and of itself mobility does not guarantee that the potential for knowledge recombination is exploited.

Overall, the link between mobility and performance requires appraisal of the context in which the knowledge recombination eventually happens. Numerous factors can emerge affecting the way in which knowledge is processed and used within organizations. Drawing from the literature on inter-organizational mobility, we conceptualize three families of context factors that potentially moderate the association of international mobile scientists and innovation performance. The three are: i) the respective attributes of the knowledge at the origin and destination, ii) the conditions of the environment under which the work is carried out with a focus on the creative intent of the 
activities conducted and iii) the attributes conferred by the position of the mobile individual (Mawdsley and Somaya, 2016).

We isolate for each one feature of particular salience in the setting of science and scientists' mobility and build for each a research hypothesis in the following three subsections.

\section{Mobility and Knowledge Concentration}

Our first context factor relates to the attributes of knowledge at the source and destination. The starting point is the observation that knowledge is often geographically localized, which has been widely discussed and documented in the literature JJaffe et al., 1993). Geographic localization of knowledge reflects the fact that knowledge is often not codified but rather tacit and lives in humans' minds (Polanyi, 1962). Tacit knowledge as well as knowledge that has yet to be codified can only be acquired through direct experience or through learning from working in close proximity to individuals versed in the knowledge (Nelson and Winter, 1985). As a consequence, the diffusion of knowledge is in part bounded by social and interpersonal connections among individuals, which lowers the barriers or costs of knowledge transfer between connected individuals but increases it between individuals who are not connected (Agrawal et al., 2006). In addition to 'tacitness' and 'embodiedness', other types of localization forces (often referred to as 'Marshallian externalities') are sometimes in place, such as industrial specialization economies (e.g., infrastructures) and job market matching effects, which can also prevent the spread of knowledge (Breschi and Lissoni, 2001).

The degree to which a certain kind of knowledge is geographically concentrated, therefore, reflects the strength of the localization forces in inhibiting the exploitation of knowledge. When localization forces are strong, knowledge tends to concentrate within certain areas or regions. Conversely, knowledge that can be transferred more easily and/or employed in various settings, has a greater tendency to spread-out across larger areas.

Because concentration reduces duplications and increases complementarity of the knowledge at the source and destination, it follows that in settings where knowledge is more concentrated the mobility of individuals is more important in affecting performance than in settings where knowledge is less concentrated. The underlying logic is that geographic barriers are more difficult to overcome in the former and human mobility can make a difference in moving knowledge which would otherwise be unlikely to travel (Almeida and Kogut, 1999). We therefore posit the following hypothesis:

H1. International mobility is more likely to be associated with higher performance when teams conduct research in subfields of knowledge that are geographically concentrated.

\section{Mobility and Greative Intent}

Our second context factor relates to conditions of the environment where the internationally mobile person works, with a focus on the creative intent of the activities conducted. 
Knowledge recombination is a process involving high uncertainty regarding possible outcomes (Fleming, 2001; Schilling and Green, 2011). Several scholars have investigated factors that make the combinatorial process more or less likely to result in fruitful outcomes (Verhoeven et al., 2016). A seminal work by Fleming (2001), for example, studies the knowledge recombination that occurs behind patents by looking at the technological classes that come together in patent cites. He finds that, while combinations made among rarely combined elements are associated on average with more uneven and less useful outcomes, at the same time they are associated with the likelihood of achieving extreme outcomes, including breakthroughs. A recent study of Wang et al. (2016) finds a consistent result for published scientific research.

Song et al. (2003) show that the knowledge brought by mobile individuals to hiring firms is less likely to be reused when the recruit is employed in activities that are wellknown and core in the organization of destination. They posit that organizational routines and path dependency constrain the usage of the mobile person's knowledge. In other words, even when new combinations are made possible thanks to the new stock of knowledge brought by mobile individuals, it is the need to perform creative activities and solve new sets of problems that makes organizations receptive to the new information and creates an appetite for searching and generating new combinations.

We, therefore, expect that the correlation of knowledge recombination enabled by international mobility and superior performance is related to performing activities that require strong creative intent. The hypothesis is based on the observation that scientific research projects involve various degrees of novelty. The majority of scientific work is aimed at expanding, testing and generalizing prior findings. It is common for scientists to pursue research on long-term projects and known areas of investigation, because this allows them to exploit the background knowledge, strategies and mental models acquired during prior research. A recent work estimates that a maximum of 11 per cent of the scientific papers in all subjects in 2001 could be considered creative, based on making novel knowledge combinations (Wang et al., 2016). It is less common for scientists to engage in entirely new streams of investigation, or to address themes where prior knowledge is extremely limited, or to tackle problems with an entirely new strategy. The social studies of science are also permeated by the idea that multi-disciplinarity is one area that involves stronger experimentation and creativity, because problem solving strategies often rely on combining epistemologies of two or more disciplines (Hargadon and Sutton, 1997; Lee et al., 2015).

Our second hypothesis is therefore:

H2. International mobility is more likely to be associated with higher performance when teams engage in activities that have a strong creative intent.

\section{Mobility and Decision Power}

A third and final context factor relates to the attributes conferred by the position of the internationally mobile person in the team of destination. A salient attribute of internationally mobile scientists relates to the position that they occupy within the team, which - we 
speculate - affects the opportunity and capacity of the scientists to use their knowledge. Drawing on the discussion of Section 2, a salient feature of science lab teams relates to their organizational structure that places principal investigators in a managerial position over other members of the team. We posit that scientists are more likely to put their knowledge to use and to recombine it with local knowledge if they serve as principal investigators in the science team, due to the decision power and managerial role associated with the principal investigator position, compared to those who serve in other positions in the team. Based on the four dimensions that define managers' power in classical organization theory, i.e., structural, ownership, expert and prestige power (Finkelstein, 1992), the position of principal investigators in science-lab teams has a close resemblance with that of top managers in companies. Principal investigators typically have formal authority over their staff, they act in the capacity of agents in all relationships between the team and the department or school of affiliation, they usually are more senior, hence more knowledgeable. Moreover, they generally enjoy more external recognition than do other members of the lab, reflected by the fact that it is not uncommon, at least in the United States, for the lab to bear the name of the principal investigator (Stephan, 2012).

The power exerted by those who occupy the principal investigator position has three main implications, which, we argue, affect the opportunity and capacity of individuals to make use of their knowledge. The first is that principal investigators control the resources used by the rest of the team. For example, they control and administer lab funding, are responsible for hiring and firing the staff, have considerable influence in choosing the PhD students and postdoctoral researchers who work in the lab, allocate research assignments and roles, as well as resources (such as usage of lab space) and are instrumental in gaining access to the infrastructures shared with the department or school. Resource control conveys key influence power on strategic decision making, like which goals to pursue, and which approach or strategy to pursue (Finkelstein, 1992; Haleblian and Finkelstein, 1993). This is the first reason leading us to argue that individuals sitting in the position of principal investigator have more opportunity and greater capacity to employ the array of knowledge, strategies, routines, and mental models that they have acquired in prior experience, compared to individuals who do not sit in such positions. A second line of argument is that expertise and prestige power confer higher status within teams and status confers deference (Ibarra and Andrews, 1993; Joshi and Knight, 2014). Deference is the capacity to have one's views, insights and opinions listened to and followed and it refers to the social perception of competence, rather than to the actual competence of an individual (Bunderson, 2003a,b; Joshi and Knight, 2014). This is a second reason to expect that the degree to which a team is willing to learn, use and capitalize on the prior experience of an internationally mobile person is greater when the internationally-mobile person is the team's principal investigator. A third and final implication of the structure of labs and the ownership of power enjoyed by principle investigators relates to information processing. Principal investigators sit at the top of the science lab hierarchical structure, because they formally supervise the work of each and all team members and because they are the reference point within the larger institution that hosts the lab. This special position makes them central in the information workflow within the lab and from the lab to the larger organization. A long- 
established stream of research has recognized that the design and direction of information flows within an organization affect the degree to which the organization draws upon and utilizes the knowledge and expertise of its individuals (Argyres and Silverman, 2004; Nerkar and Paruchuri, 2005). Centrality in information flows conveys more influence (Burt, 1997; Ibarra and Andrews, 1993) and decision involvement (Bunderson, 2003b), and creates ideal conditions for the mobile person's knowledge and prior expertize to be heavily used.

Given these three arguments, we posit that the degree to which the knowledge recombination potential of mobile individuals is used, and hence translates into superior innovation performance, is higher in research teams where the internationally mobile person has greater decision power (i.e., serves as the principal investigator). This leads us to formulate the following hypothesis:

H3. International mobility is more likely to be associated with higher performance when the internationally-mobile individual has decision power within the team.

\section{METHODS}

\section{Sample}

To investigate the specific research questions of this article, we make use of original data that we extract from the GlobSci Survey Data Release. ${ }^{[4]}$ The goal of the GlobSci survey was to provide consistent cross-country data on the international mobility of scientists. The sampling strategy was organized as follows. First, we chose four areas of the hard sciences: biology, chemistry, earth and environmental sciences, and materials science. The selection of fields was based in part upon the fact that it is common on publications in these fields to designate a corresponding author and list the corresponding author's email address. ${ }^{[5]}$ These are also fields in which scientific projects are usually conducted within a lab setting or a scholarly unit supervised by an academic professor, making it a suitable sample to pose questions about the performance of the team. Second, we extracted all journals that are listed in the Journal of Citations Report of ISIWeb of Knowledge in all subfields of the four areas. We divided the journals in each subfield by the respective quartile of Impact Factor (IF) and randomly picked four journals in each quartile and each subfield. This yielded a sample of journals corresponding to approximately 30 per cent of all journals in the four areas. We then collected from ISI-Web of Science all articles which appeared in the selected journals during 2009. We called these 'focal articles'. We retrieved the respective name and email address of the corresponding authors for each focal article and kept only the corresponding authors whose email address ended with one of 16 country domains. ${ }^{[6]}$ After dropping corresponding authors who appeared more than once, we obtained a final sample of 47,304 unique corresponding authors paired one-to-one to a focal paper.

The sampling strategy resulted in a final sample that comprises four disciplines, 16 countries and is stratified by IF. We administered the survey online country by country in the language of the recipient during the period February-June 2011. ${ }^{[7]}$ The invitation 
emails were sent to the corresponding author and included a link to a web interface on Qualtrics.com. The corresponding authors was asked questions concerning: i) the specific work presented in the focal paper, ii) their own position and background, with considerable focus on international mobility, and iii) the team of co-authors of the paper, in case the paper was co-authored. The questionnaire was dynamically-generated, such that in specific questions the respondent was shown the title of the paper and the name of the co-authors. This was meant to ensure that the team-level answers were not generic and could be attributed to the focal paper.

Given the choice to administer the questionnaire to the corresponding author, a discussion of the role of the corresponding author is in order. Research shows that corresponding authors are not randomly assigned but instead play a special role in the research. Haussler and Sauermann (2014) find, for example, that being a corresponding author 'is strongly predicted by conceptual contributions and writing but not by having performed the experiment' (2014, p. 24). The finding is corroborated if one considers the corresponding authors position in authors lists. By tradition, in most fields of science the principal investigator is listed as the last author of the paper. Haussler and Sauermann (2014) find that two-thirds of the corresponding authors in articles published in PLosONE are last authors; virtually all the other corresponding authors are first author. A survey of 2016 issues of the journal Science by the authors finds slightly more than 79 per cent of corresponding authors to be the last author, slightly more than 19 per cent to be the first author and the remaining 1 per cent to occupy middle-author positions

The overall response rate of the survey was 40.6 per cent and the response rate conditional on completing the entire survey was 35.6 per cent. The GlobSci data have been tested for response rate and response completion bias and have been shown to provide a fair and unbiased representation of the population of publication-active scientists in the surveyed countries and areas (Franzoni et al., 2012). It has further been tested for unbiasness concerning representatives of teams for size and IF (see Supporting information to Franzoni et al., 2012). Overall, the dataset constitutes a unique source of reliable information concerning the international mobility of scientists, the characteristics of the research underlying the focal paper, the team and position of the mobile person within the team, as well as other data that are useful for the purpose of our study. Information concerning the focal paper can be linked with citation counts and journal IF to analyse performance.

To investigate our research questions, we extract from the GlobSci Survey Data Release all answers from respondents who belong to a team of scientists composed of two or more co-authors located in the same laboratory or institution. We retrieve information on the international mobility status of the corresponding author based on moving to a country different from that of origin in adult age. Country of origin of the corresponding author was coded as the country in which the respondent was living at the age of 18 and international mobility was coded only for work or study and not for short-term periods of work or study. Because of our focus on teams, by sample construction we exclude all solo-authors. To minimize the potential incidence of confounding factors, we also exclude two other kinds of respondents/focal articles. First, we exclude focal articles which have one or more co-authors located in a different institution and/ or in a different country because external collaboration would offer an alternative channel to that of the scientist's mobility as a source of distant knowledge. Second, we 
exclude respondents who had previous experience of work or study abroad and returned to their origin country (i.e., returnees), such that we keep only corresponding authors who are either natives of the country where they work and have never experienced international mobility, or international movers who are working away from their origin country. The decision to exclude 'returnees' from the analysis is motivated by the need to eliminate factors that could potentially confound the analysis given that the decision to return could be both positively and negatively related to the skill level of the individual and be country-specific over time (Borjas and Bratsberg, 1996). The criteria for inclusion resulted in a final sample of 4336 unique pairs of focal article and research teams. Of these, approximately 30 per cent were teams whose corresponding author was an internationally mobile scientist and 70 per cent were teams whose corresponding author was a non-mobile scientist.

\section{Variables}

The aim of this paper is to examine the presence of performance premiums for teams that have an internationally mobile scientist and, to the extent that it exists, relate it to the three specific context factors discussed above. These are the degree of geographic concentration of the respective scientific knowledge; the level of creative intent of the tasks associated with the focal paper; and whether or not the mobile scientist has the decision power associated with being the team's principal investigator. We measure performance by the IF of the journal in which each focal article is published as well as the total number of forward citations received. We use a 3-year time window and a 6-year time window, as robustness check, to measure citations.

The three context factors were operationalized as follows.

Degree of geographic concentration of knowledge. For each focal article the level of geographic concentration of the relevant knowledge is computed by measuring the degree of dispersion across countries worldwide of scientific articles published in the same subfield. In particular, we have computed a Herfindahl-Hirschman Index (HHI) based on the countries' share of publications in the specific subfield of each focal article, using cumulated publication data for the years 1996-2010. Data on countries' number of publication by scientific subfield have been retrieved from the SCImago database. ${ }^{[8]}$ Higher values of the HHI index indicate that a particular focal article, i.e., the outcome of one of the analysed teams, is in a scientific domain with relatively less international dispersion of knowledge. We have then generated a dummy variable (CONG KNOWLEDGE) that equals one if a focal article is in a subfield with a high geographic concentration of knowledge, where the threshold is set at the top 25 per cent of the distribution of HHI across all subfields. As a robustness check, we set the threshold at the top 10 per cent of the distribution.

Creative intent. We make use of self-reported measures in order to operationalize a variable regarding the creative intent of the specific research project on which the team worked. In particular, respondents were asked to rate on a 1 to 5 scale both the level of creativity and the level of multidisciplinarity of the research activities upon which the focal paper was based. ${ }^{[9]}$ Both creativity and multidisciplinarity are arguably 
related to the level of novelty of the research project and involve processes of knowledge recombination. In order to characterize the focal papers we apply a Cronbach Alpha method to the data for the two questions and generate a combined variable. ${ }^{[10]}$ We then set a threshold at four on the combined variable to generate a dummy variable (CREATIVE), which is expected to identify those focal articles that likely required significant recombination of different pieces of scientific knowledge. Given the self-reported nature of the variable CREATIVE we perform a number of tests to assess its reliability, using bibliometric indicators based on backward citations. See subsection 4.4 for details.

Decision power. We are interested in identifying individuals who sit in positions of high decision power in their teams. Given that the sample we are analysing is composed of research units of scientists working in academia or in public research centres, we set the dummy variable POWER equal to one for corresponding authors who were either professors in academic institutions or research scientists in public research institutions (such as 'chercheurs' at the French CNRS, etc.) The assumption is that corresponding authors who hold such titles act as principal investigators in the lab. The finding that the vast majority of corresponding authors appear in the last author position, coupled with the strong tradition in many scientific fields of assigning the last author position to the principal investigator (Black and Stephan, 2010), is consistent with this assumption. The POWER variable takes a value of zero for PhDs, Postdocs, research fellows and technicians.

In order to check that our measure corresponds to the position of power ascribed to that of the principal investigator, we exploit additional information collected in the survey about the main role played by the respondent in the focal paper. The data reported in Table I suggest that corresponding authors who we infer to be principal investigators are more likely to be involved in activities such as the formulation of the initial idea and the contribution to the theory that likely reflect decision-making power in teams. On the other hand, they tend to be underrepresented in roles that involve mostly the execution of research activities. We note that this is consistent with Haeussler and Sauermann's (2014) findings regarding corresponding authors, noted above.

Table I. Main role in the paper of the respondent by status

\begin{tabular}{lrrr}
\hline Main role in the paper & POWER & NO POWER & Diff. \\
\hline Formulating the initial idea & $38.75 \%$ & $14.88 \%$ & 23.87 \\
Contributing to the theory and background & $5.45 \%$ & $4.13 \%$ & 1.32 \\
Framing and writing the article & $19.38 \%$ & $23.76 \%$ & -4.38 \\
Doing the heavy-lifting (Execution of research activities) & $18.99 \%$ & $49.79 \%$ & -30.8 \\
Doing the data analysis & $1.17 \%$ & $2.89 \%$ & -1.72 \\
Supervising the work of others & $13.15 \%$ & $3.10 \%$ & 10.05 \\
Providing the funding & $1.79 \%$ & $0.21 \%$ & 1.58 \\
Other $(<1 \%)$ & $1.33 \%$ & $1.24 \%$ & 0.09 \\
Total & $100 \%$ & $100 \%$ & \\
& & & \\
\hline
\end{tabular}

*Decision power is conferred by occupying a principal investigator position in the team. 
Note that the statistics reported in Table I are based on all teams. The evidence is confirmed when the sample is restricted to teams with an above average size in our sample (i.e., more than four members).

Other control variables. For each respondent and related focal paper we make use of a set of control variables. Such variables include age, gender, dummies for the country of residence at the time the survey was administered, and team size. Moreover, we construct a variable designed to capture the level of scientific standing of the respondent's country of origin. In particular, we use the Hirsch index ${ }^{[11]}$ computed for publications of a specific country in the time window 1996-2010 and extracted from the SCImago database. ${ }^{[12]}$ The higher is the variable (H INDEX ORIGIN) the higher is the number of highly cited publications from that country.

In Table II we summarize the way in which each variable was constructed. Table III provides summary statistics for all variables used in subsequent models and also reports summary statistics for a set of split variables that are based on the intersection between the mobility status (MOBILE-SCIENTIST TEAM) of the respondent and the context factors analysed (CONG KNOWLEDGE, CREATIVE, POWER). Table AI in the Appendix shows the correlation matrix for the variables used in the econometric models. Finally, in Table IV we present the summary statistics of our main variables by the international mobility status of the respondent. The univariate analysis indicates that on average the focal papers of mobile-scientist teams have a significantly higher IF and a

Table II. Variables description

\begin{tabular}{|c|c|}
\hline Variables & Description \\
\hline IMPACT FACTOR & Impact factor of the journal in which the focal article has appeared \\
\hline TOTAL 3 YEAR GITATIONS & Cumulated number of citations received by focal article in 3 years \\
\hline TEAM SIZE & Number of co-authors of the focal article \\
\hline AGE & Age of respondent at the time of the survey \\
\hline FEMALE & Gender dummy \\
\hline H INDEX ORIGIN & Hirsch index of the country of origin of the respondent/1000 \\
\hline MOBILE-SCIENTIST TEAM & $\begin{array}{l}\text { Dummy equal to one if the respondent is an international mobile } \\
\text { researcher }\end{array}$ \\
\hline POWER & $\begin{array}{l}\text { Dummy equal to one if the respondent is a professor at an academic } \\
\text { institution or a research scientist at a public research centre }\end{array}$ \\
\hline CONG KNOWLEDGE & $\begin{array}{l}\text { Dummy equal to one if the article is in a subfield with a high geo- } \\
\text { graphic concentration of knowledge (top } 25 \% \text { of the distribution } \\
\text { across all subfields of the Herfindahl-Hirschman concentration } \\
\text { index) }\end{array}$ \\
\hline CREATIVE & $\begin{array}{l}\text { The variable is based on the combination of two self-reported char- } \\
\text { acteristics of the focal article: level of multi-disciplinarity and level of } \\
\text { creativity of the task. The two characteristics are measured on a 1-5 } \\
\text { scale. These variables have been combined with a Cronbach Alpha } \\
\text { approach. } \\
\text { The dummy is equal to one if the combined variable is higher than } \\
4 \text {. }\end{array}$ \\
\hline
\end{tabular}


Table III. Variables summary statistics

\begin{tabular}{|c|c|c|c|c|c|}
\hline VARLABLES & $O B S$ & $M E A \mathcal{N}$ & $S T D D V$ & $M I \mathcal{N}$ & $M A X$ \\
\hline IMPACT FACTOR & 4,348 & 3.654 & 3.216 & 0 & 32.233 \\
\hline TOTAL 3 YEAR CITATIONS & 4,348 & 8.449 & 11.784 & 0 & 202 \\
\hline TEAM SIZE & 4,348 & 3.994 & 2.027 & 2 & 21 \\
\hline AGE & 4,348 & 47.104 & 10.805 & 25 & 85 \\
\hline FEMALE & 4,348 & 0.239 & 0.426 & 0 & 1 \\
\hline H INDEX ORIGIN & 4,348 & 0.656 & 0.373 & 0.008 & 1.229 \\
\hline MOBILE-SGIENTIST TEAM & 4,348 & 0.308 & 0.462 & 0 & 1 \\
\hline GONG KNOWLEDGE & 4,297 & 0.269 & 0.443 & 0 & 1 \\
\hline GONG KNOWLEDGE MOBILE & 4,297 & 0.091 & 0.288 & 0 & 1 \\
\hline NON GONG KNOWLEDGE MOBILE & 4,297 & 0.215 & 0.411 & 0 & 1 \\
\hline GONG KNOWLEDGE NONMOBILE & 4,297 & 0.178 & 0.382 & 0 & 1 \\
\hline POWER & 4,336 & 0.727 & 0.445 & 0 & 1 \\
\hline POWER MOBILE & 4,336 & 0.209 & 0.407 & 0 & 1 \\
\hline NON POWER MOBILE & 4,336 & 0.099 & 0.299 & 0 & 1 \\
\hline POWER NONMOBILE & 4,336 & 0.518 & 0.500 & 0 & 1 \\
\hline GREATIVE & 4,336 & 0.375 & 0.484 & 0 & 1 \\
\hline CREATIVE MOBILE & 4,336 & 0.132 & 0.341 & 0 & 1 \\
\hline NON GREATIVE MOBILE & 4,336 & 0.167 & 0.373 & 0 & 1 \\
\hline GREATIVE NONMOBILE & 4,336 & 0.243 & 0.432 & 0 & 1 \\
\hline BIOLOGY & 4,348 & 0.312 & 0.463 & 0 & 1 \\
\hline CHEMISTRY & 4,348 & 0.335 & 0.472 & 0 & 1 \\
\hline EARTH SCIENCE & 4,348 & 0.181 & 0.385 & 0 & 1 \\
\hline MATERIAL SCIENCE & 4,348 & 0.172 & 0.378 & 0 & 1 \\
\hline
\end{tabular}

larger number of 3-year citations. They also have a slightly lower number of co-authors. Females are underrepresented among mobile scientists. As expected, the variable capturing the average scientific standing of the origin country of respondents (H INDEX ORIGIN) is lower for the subset of mobile scientist, reflecting the fact that generally international mobility flows are directed towards countries with more advanced scientific systems.

Table IV. Summary statistics by mobility status

\begin{tabular}{|c|c|c|c|c|c|c|}
\hline & \multicolumn{2}{|c|}{$\begin{array}{l}\text { MOBILE-SCIEN- } \\
\text { TIST TEAM } \\
\end{array}$} & \multicolumn{2}{|c|}{$\begin{array}{l}\text { NONMOBILE SC. } \\
\text { TEAM }\end{array}$} & \multirow{2}{*}{ DIFF } & \multirow{2}{*}{ P-value } \\
\hline & Mean & Std err & Mean & Std err & & \\
\hline IMPACT FACTOR & 4.052 & 0.090 & 3.476 & 0.057 & -0.575 & 0.00 \\
\hline 3 YEAR CITATIONS & 10.664 & 0.410 & 7.462 & 0.179 & -3.202 & 0.00 \\
\hline TEAM SIZE & 3.847 & 0.054 & 4.059 & 0.037 & 0.212 & 0.00 \\
\hline AGE & 46.059 & 0.292 & 47.569 & 0.197 & 1.509 & 0.00 \\
\hline FEMALE & 0.209 & 0.011 & 0.251 & 0.007 & 0.042 & 0.00 \\
\hline H INDEX ORIGIN & 0.388 & 0.006 & 0.774 & 0.006 & 0.3860 & 0.00 \\
\hline
\end{tabular}




\section{Model Design and Results}

In this section, we present the modelling approach used to test the research hypotheses concerning links between international mobility of the corresponding author and the performance of the associated team. We measure performance by both the IF of the scientific journal in which the focal article has appeared and the total number of citations received by the article after publication, in a time window of both three years and six years (for robustness). In all model specifications we include a set of field dummies to account for structural differences among scientific domains in citation patterns and IF distribution.

At the individual level, we control for the age of the respondent (AGE), the size of the research team (SIZE), a gender dummy (FEMALE) and a variable that captures the level of scientific standing of the origin country of the respondent in the specific scientific domain (H INDEX). We also include a set of country dummies for the 16 core countries in which respondents are located. We first estimate a baseline model assessing the presence and magnitude of a performance premium for the mobile-scientist teams, net of the effects related to country-specific and field-specific factors. This baseline model also includes the three context dummy variables for degree of geographic concentration of knowledge, level of creative intent of the focal paper and decision power. We then estimate a set of models designed to analyse the influence of context factors (HP 1 to HP 3), differentiating between mobile and non-mobile-scientist teams and test the equality of the estimated coefficients by means of Wald tests.

The estimates presented in Table $\mathrm{V}$ indicate the presence of a significant performance premium for the mobile-scientist teams that holds after accounting for individual controls and for the characteristics of the focal article. As expected, the H-index of the country of origin is positively correlated with the quality of the research output. This variable - in the case of mobile individuals - captures the high heterogeneity in the scientific standing of the origin countries from which the mobile scientists come. The positive coefficient of TEAM SIZE shows that larger teams tend to outperform smaller ones. Columns II-IV in Table V add context variables, one at a time, to the baseline equation.

Regardless of the model specification, all estimates reported in Table V suggest the existence of a robust positive correlation between performance and the presence of internationally mobile scientists on the team. We check for potential issues of multicollinearity by analysing the Variance Inflation Factors (VIF) across the different model specifications. VIFs appear at regular values, suggesting that multicollinearity raises no problem in the estimates. ${ }^{[13]}$ The estimates also show that, on average, performance is positively correlated with the degree of geographic concentration of knowledge in the respective subfield (CONC KNOWLEDGE), with research projects involving more creative research activities (CREATIVE) and with teams whose corresponding authors have decision power (POWER).

We deepen the analysis in the following by testing whether the three kinds of context factors exert differential impacts on the performance of mobile-scientist teams and nonmobile-scientist teams. In some of these estimates we make use of institution-level dummies. In this case, the mobility premium should be net of institution-specific 
Table V. Baseline model on performance and mobility status

\begin{tabular}{|c|c|c|c|c|}
\hline MODEL & $I$ & $I I$ & III & $I V$ \\
\hline MOBILE-SCIENTIST TEAM & $\begin{array}{l}0.7091^{\text {**** }} \\
(0.142)\end{array}$ & $\begin{array}{l}0.7161^{\text {**** }} \\
(0.143)\end{array}$ & $\begin{array}{l}0.6934^{* * * *} \\
(0.143)\end{array}$ & $\begin{array}{l}0.6913^{\text {**** }} \\
(0.144)\end{array}$ \\
\hline POWER & & $\begin{array}{l}0.4374^{* * * *} \\
(0.109)\end{array}$ & $\begin{array}{l}0.4118^{* * * *} \\
(0.109)\end{array}$ & $\begin{array}{l}0.4092^{* * * *} \\
(0.109)\end{array}$ \\
\hline CREATIVE & & & $\begin{array}{l}0.7091^{\text {**** }} \\
(0.100)\end{array}$ & $\begin{array}{l}0.7001^{\text {**** }} \\
(0.100)\end{array}$ \\
\hline CONG KNOWLEDGE & & & & $\begin{array}{l}0.4222^{* * * *} \\
(0.124)\end{array}$ \\
\hline TEAM SIZE & $\begin{array}{l}0.2459^{* * * *} \\
(0.038)\end{array}$ & $\begin{array}{l}0.2471 * * * * \\
(0.038)\end{array}$ & $\begin{array}{l}0.2308 * * * \\
(0.038)\end{array}$ & $\begin{array}{l}0.2249^{* * * *} \\
(0.038)\end{array}$ \\
\hline AGE & $\begin{array}{l}-0.0145^{* * * *} \\
(0.004)\end{array}$ & $\begin{array}{l}-0.0217^{* * * *} \\
(0.005)\end{array}$ & $\begin{array}{l}-0.0216^{* * *} \\
(0.005)\end{array}$ & $\begin{array}{l}-0.0220^{* * *} \\
(0.005)\end{array}$ \\
\hline FEMALE & $\begin{array}{l}-0.2554^{* *} \\
(0.115)\end{array}$ & $\begin{array}{l}-0.2308^{* * *} \\
(0.114)\end{array}$ & $\begin{array}{l}-0.2156^{*} \\
(0.113)\end{array}$ & $\begin{array}{l}-0.2187 * \\
(0.114)\end{array}$ \\
\hline H INDEX ORIGIN & $\begin{array}{l}1.0339 * * * \\
(0.211)\end{array}$ & $\begin{array}{l}1.0067 * * * \\
(0.211)\end{array}$ & $\begin{array}{l}1.0905^{* * * *} \\
(0.212)\end{array}$ & $\begin{array}{l}1.0946^{* * * *} \\
(0.215)\end{array}$ \\
\hline CONSTANT & $\begin{array}{l}1.8108^{* * * *} \\
(0.487)\end{array}$ & $\begin{array}{l}1.8499 * * * * \\
(0.484)\end{array}$ & $\begin{array}{l}1.6467 * * * * \\
(0.471)\end{array}$ & $\begin{array}{l}1.6125 * * * \\
(0.469)\end{array}$ \\
\hline Field dummies & $\mathrm{Y}$ & $\mathrm{Y}$ & $\mathrm{Y}$ & $\mathrm{Y}$ \\
\hline Country dummies & $\mathrm{Y}$ & $\mathrm{Y}$ & $\mathrm{Y}$ & $\mathrm{Y}$ \\
\hline Observations & 4,348 & 4,336 & 4,336 & 4,297 \\
\hline $\mathrm{R}$-sq & 0.144 & 0.147 & 0.158 & 0.163 \\
\hline F stat & $31.2^{* * * *}$ & $30.0^{* * * *}$ & $29.1 * * *$ & $28.3^{* * *}$ \\
\hline
\end{tabular}

Notes: OLS model. Dependent variable: Impact Factor.

Heteroskedasticty robust standard errors. Significance level: *** 99\%; ** 95\%; * 90\%.

characteristics that might induce spurious effects on our estimates (e.g., a higher systematic propensity of a certain institution to pursue more creative research). ${ }^{[14]}$ Note that in order to use institution dummies we must limit the sample to those institutions for which we have a minimum number of observations. ${ }^{[15]}$ We use as a dependent variable both the IF of the focal article and total 3-year citations. Given the count nature of the latter variable, we use Poisson count data models and we report incidence rate ratios rather than coefficients, so as to provide a more direct interpretation of the magnitude of the covariates. ${ }^{[16]}$

In Table VI we address our first research hypothesis. We split mobile and nonmobile-scientist teams into subgroups that either work or do not work in subfields characterized by high knowledge concentration. The omitted group is represented by nonmobile-scientist teams working in non-geographically concentrated research subfields. Results indicate that knowledge concentration plays a relevant role in explaining the superior average performance of the teams with an internationally mobile corresponding author. Indeed, the decomposition of the performance premium for subgroups of mobile and non-mobile-scientist teams reveals that mobile-scientist teams working in highly concentrated subfields of knowledge (CONG KNOWLEDGE MOBILE) not only outperform non-mobile-scientist teams (at 99 per cent confidence level), but also 
Table VI. Team performance and mobility

\begin{tabular}{|c|c|c|c|}
\hline MODELS & $I$ & II & $I I I$ \\
\hline DEP VAR & $\begin{array}{l}\text { IF } \\
\text { OLS }\end{array}$ & $\begin{array}{l}\text { Citations } \\
\text { Poisson (irr reported) }\end{array}$ & $\begin{array}{l}\text { Citations } \\
\text { Poisson (irr reported) }\end{array}$ \\
\hline CONC KNOWLEDGE MOBILE & $\begin{array}{l}1.3039 * * * \\
(0.237)\end{array}$ & $\begin{array}{l}1.6445^{* * *} \\
(0.036)\end{array}$ & $\begin{array}{l}1.3879 * * * \\
(0.046)\end{array}$ \\
\hline $\begin{array}{l}\text { NON CONC KNOWLEDGE } \\
\text { MOBILE }\end{array}$ & $\begin{array}{l}0.5531^{* * * *} \\
(0.143)\end{array}$ & $\begin{array}{l}1.3535^{* * *} \\
(0.026)\end{array}$ & $\begin{array}{l}1.2985^{* * * *} \\
(0.037)\end{array}$ \\
\hline $\begin{array}{l}\text { CONC KNOWLEDGE } \\
\text { NONMOBILE }\end{array}$ & $\begin{array}{l}0.2570^{*} \\
(0.154)\end{array}$ & $\begin{array}{l}0.9812 \\
(0.016)\end{array}$ & $\begin{array}{l}0.9634^{*} \\
(0.020)\end{array}$ \\
\hline POWER & $\begin{array}{l}0.4056^{* * * *} \\
(0.109)\end{array}$ & $\begin{array}{l}1.1392^{* * * *} \\
(0.016)\end{array}$ & $\begin{array}{l}1.1594^{* * * *} \\
(0.023)\end{array}$ \\
\hline CREATIVE & $\begin{array}{l}0.7001^{* * *} \\
(0.100)\end{array}$ & $\begin{array}{l}1.2292^{* * * *} \\
(0.013)\end{array}$ & $\begin{array}{l}1.2352^{* * * *} \\
(0.017)\end{array}$ \\
\hline TEAM SIZE & $\begin{array}{l}0.2239 * * * \\
(0.038)\end{array}$ & $\begin{array}{l}1.0937 * * * \\
(0.002)\end{array}$ & $\begin{array}{l}1.0755^{* * * *} \\
(0.003)\end{array}$ \\
\hline AGE & $\begin{array}{l}-0.0221 * * * \\
(0.005)\end{array}$ & $\begin{array}{l}0.9891 * * * \\
(0.001)\end{array}$ & $\begin{array}{l}0.9880^{* * * *} \\
(0.001)\end{array}$ \\
\hline FEMALE & $\begin{array}{l}-0.2163^{*} \\
(0.114)\end{array}$ & $\begin{array}{l}0.9158^{* * *} \\
(0.012)\end{array}$ & $\begin{array}{l}0.8792^{* * * *} \\
(0.015)\end{array}$ \\
\hline H INDEX ORIGIN & $\begin{array}{l}1.1100^{* * * *} \\
(0.215)\end{array}$ & $\begin{array}{l}1.3183^{* * * *} \\
(0.031)\end{array}$ & $\begin{array}{l}1.2575^{* * * *} \\
(0.043)\end{array}$ \\
\hline CONSTANT & $\begin{array}{l}1.6883^{* * * *} \\
(0.468)\end{array}$ & $\begin{array}{l}5.6109^{* * * *} \\
(0.357)\end{array}$ & $\begin{array}{l}16.4555^{* * *} \\
(4.762)\end{array}$ \\
\hline Filed dummies & $\mathrm{Y}$ & $\mathrm{Y}$ & Y \\
\hline Country dummies & $\mathrm{Y}$ & $\mathrm{Y}$ & $\mathrm{Y}$ \\
\hline Institution dummies & $\mathrm{N}$ & $\mathrm{N}$ & $\mathrm{Y}$ \\
\hline Observations & 4,297 & 4,297 & 2,602 \\
\hline $\mathrm{R}-\mathrm{Sq}$ & 0.164 & & \\
\hline Pseudo R-Sq & & 0.1167 & 0.2035 \\
\hline LR Chi-Sq & & $6585.1 * * *$ & $7305.9 * * *$ \\
\hline $\begin{array}{l}\text { F stat } \\
\text { P value of Wald test on coefficients } \\
\text { differences: }\end{array}$ & $27.7 * * *$ & & \\
\hline $\begin{array}{l}\text { CONC KNOW MOBILE - NON } \\
\text { CON KNOW MOBILE }\end{array}$ & 0.000 & 0.000 & 0.081 \\
\hline $\begin{array}{l}\text { CONC KNOW MOBILE - CONG } \\
\text { KNOW NONMOBILE }\end{array}$ & 0.000 & 0.000 & 0.000 \\
\hline
\end{tabular}

Notes: Teams grouped according to the degree of geographic concentration of the knowledge. Dependent variable: IF and 3 year total citations. OLS and Poisson models

Heteroskedasticity robust standard errors. Significance level: *** 99\%; **95\%; *90\%.

show a significantly higher performance than mobile-scientist teams working in fields with less concentrated knowledge (NON GONG KNOWLEDGE MOBILE). This evidence holds in models where citations are used as the dependent variable, rather than IF, and when institution-level dummies are included in a reduced-sample (Model III in Table VI). In terms of magnitude of the effects, model II in Table VI indicates that 
mobile-scientist teams working in highly-concentrated fields have 64.4 per cent more citations than the baseline reference group, i.e., non-mobile-scientist teams working in non-concentrated fields, holding the other variable constant in the model. The performance premium is lower (35.3 per cent) in the case of mobile-scientist teams working in non-concentrated fields and the difference remains statistically significant. Note that the presented results are confirmed when using alterative thresholds for the identification of highly-concentrated fields ${ }^{[17]}$. The result is consistent with HP1 and the idea that one driver of the mobility-performance correlation is the ability of mobile individuals to recombine pieces of knowledge that are unevenly spread and whose transfer requires physical mobility.

In Table VII we focus on our second hypothesis and analyse the presence of significant differences in the performance of mobile-scientist teams and non-mobile-scientist teams when working on research activities that have a strong creative intent. We have seen that, on average, more creative focal papers are associated with higher performance. Interestingly, and important for this research, results from Table VII highlight that such performance correlation is not equally in place for all the subgroups. In particular, the result of the Wald test shows that mobile-scientist teams involved in creative activities outperform mobile-scientist teams not involved in creative activities. Furthermore, mobile-scientist teams engaging in activities with high creative intent outperform non-mobile-scientist teams involved in creative activities. In model III of Table VII, where we use institution dummies, we observe a significant additional citation premium for mobile-scientist teams when working on highly creative research tasks of about 35.5 per cent with respect to the reference group.

Finally, in Table VIII we split the mobile and non-mobile-scientist teams into subgroups based on whether the corresponding author has or does not have decision power within the team. Our H3 suggests that the mobility-performance premium should be larger when the mobile person works in a position that gives decision power. Results strongly support this hypothesis, showing that mobile-scientist teams where the mobile person has decision power outperform mobile-scientist teams where the mobile person does not have decision power and that teams with mobile individuals having high decision power outperform teams with non-mobile individuals having high decision power (at 99 per cent confidence level).

\section{Robustness Checks}

In this section we illustrate various robustness checks that we performed in order to test the reliability of our analyses. The robustness checks pertain to two main areas: the validation of self-reported measures from the GlobSci survey and the assessment of potential spurious correlation due to potentially unobserved factors.

Concerning the validity of the self-reported measures regarding the degree of creativity and multidisciplinarity that form the variable of creative intent (CREATIVE), we look at the correlation of the variable with alternative measures of novelty and multidisciplinarity at the paper-level that are based on bibliometric indicators. We have implemented a two-pronged approach. First, we collected all backward citations for a random sample covering 60 per cent of the analysed 
Table VII. Team performance and mobility

\begin{tabular}{|c|c|c|c|}
\hline MODELS & $I$ & II & $I I I$ \\
\hline \multirow[t]{2}{*}{ DEP VAR } & IF & Citations & Citations \\
\hline & OLS & Poisson (irr reported) & Poisson (irr reported) \\
\hline \multirow[t]{2}{*}{ CREATIVE MOBILE } & $1.2945 * * *$ & $1.7985^{* * *}$ & $1.6984 * * *$ \\
\hline & $(0.181)$ & $(0.038)$ & $(0.054)$ \\
\hline \multirow{2}{*}{$\begin{array}{l}\text { NON CREATIVE } \\
\text { MOBILE }\end{array}$} & $0.7775^{* * *}$ & $1.4167 * * *$ & $1.3433^{* * *}$ \\
\hline & $(0.162)$ & $(0.028)$ & $(0.040)$ \\
\hline \multirow{2}{*}{$\begin{array}{l}\text { CREATIVE } \\
\text { NONMOBILE }\end{array}$} & $0.8116^{* * *}$ & $1.2061^{* * *}$ & $1.2160 * * *$ \\
\hline & $(0.125)$ & $(0.017)$ & $(0.021)$ \\
\hline \multirow[t]{2}{*}{ POWER } & $0.4099 * * *$ & $1.1319 * * *$ & $1.1483^{* * *}$ \\
\hline & $(0.111)$ & $(0.017)$ & $(0.023)$ \\
\hline \multirow[t]{2}{*}{ CONG KNOWLEDGE } & $0.3928 * * *$ & $1.0729 * * *$ & 1.0070 \\
\hline & $(0.125)$ & $(0.014)$ & $(0.018)$ \\
\hline \multirow[t]{2}{*}{ TEAM SIZE } & $0.2307 * * *$ & $1.0938^{* * *}$ & $1.0741^{* * * *}$ \\
\hline & $(0.039)$ & $(0.002)$ & $(0.003)$ \\
\hline \multirow[t]{2}{*}{ AGE } & $-0.0221 * * *$ & $0.9891^{* * * *}$ & $0.9879 * * *$ \\
\hline & $(0.005)$ & $(0.001)$ & $(0.001)$ \\
\hline \multirow[t]{2}{*}{ FEMALE } & $-0.2052^{*}$ & $0.9195^{* * *}$ & $0.8811^{* * * *}$ \\
\hline & $(0.117)$ & $(0.012)$ & $(0.015)$ \\
\hline \multirow[t]{2}{*}{ H INDEX ORIGIN } & $1.0675^{* * *}$ & $1.3108^{* * *}$ & $1.2885^{* * * *}$ \\
\hline & $(0.211)$ & $(0.032)$ & $(0.045)$ \\
\hline \multirow[t]{2}{*}{ CONSTANT } & $1.6204^{* * *}$ & $5.3955^{* * *}$ & $16.2842^{* * *}$ \\
\hline & $(0.478)$ & $(0.349)$ & $(4.871)$ \\
\hline Filed dummies & Y & Y & $\mathrm{Y}$ \\
\hline Country dummies & $\mathrm{Y}$ & $\mathrm{Y}$ & $\mathrm{Y}$ \\
\hline Institution & $\mathrm{N}$ & $\mathrm{N}$ & $\mathrm{Y}$ \\
\hline Observations & 4,151 & 4,151 & 2,512 \\
\hline R-Sq/Pseudo R-Sq & 0.1641 & 0.1139 & 0.201 \\
\hline LR Chi-Sq & & $6238.5^{* * *}$ & $6938.9^{* * * *}$ \\
\hline F stat & $26.8^{* * *}$ & & \\
\hline \multicolumn{4}{|l|}{$\begin{array}{l}\mathrm{P} \text { value of Wald test on } \\
\text { coefficients differences: }\end{array}$} \\
\hline $\begin{array}{l}\text { CREATIVE MOBILE - } \\
\text { NON CREATIVE } \\
\text { MOBILE }\end{array}$ & 0.002 & 0.000 & 0.000 \\
\hline CREATIVE MOBILE - & 0.016 & 0.000 & 0.000 \\
\hline CREATIVE & & & \\
\hline NONMOBILE & & & \\
\hline
\end{tabular}

Notes. Teams grouped according to the level of creative intent of the research activities. Dependent variables: impact factor and 3 year total citations. OLS and Poisson models

Heteroskedasticty robust standard errors. Significance level: *** 99\%; ** 95\%; *90\%.

focal papers. The backward citations were grouped by scientific subfields, using the Web of Science classification and we collected data on the number of different scientific subfields in which the journal of the focal paper is classified. Based on these data, we computed a number of indicators of the degree of dispersion of 
Table VIII. Team performance and mobility

\begin{tabular}{|c|c|c|c|}
\hline MODELS & $I$ & $I I$ & III \\
\hline DEP VAR & $\begin{array}{l}\text { IF } \\
\text { OLS }\end{array}$ & $\begin{array}{l}\text { Citations } \\
\text { Poisson (irr reported) }\end{array}$ & $\begin{array}{l}\text { Citations } \\
\text { Poisson (irr reported) }\end{array}$ \\
\hline POWER MOBILE & $\begin{array}{l}1.1178^{* * * *} \\
(0.186)\end{array}$ & $\begin{array}{l}1.6368 * * * \\
(0.037)\end{array}$ & $\begin{array}{l}1.5158^{* * *} \\
(0.050)\end{array}$ \\
\hline NON POWER MOBILE & $\begin{array}{l}0.4256^{* *} \\
(0.184)\end{array}$ & $\begin{array}{l}1.3429 * * * \\
(0.033)\end{array}$ & $\begin{array}{l}1.1104^{* * *} \\
(0.039)\end{array}$ \\
\hline POWER NONMOBILE & $\begin{array}{l}0.2711 * * \\
(0.121)\end{array}$ & $\begin{array}{l}1.0892^{* * *} \\
(0.020)\end{array}$ & $\begin{array}{l}1.0298 \\
(0.025)\end{array}$ \\
\hline CREATIVE & $\begin{array}{l}0.6978^{* * *} \\
(0.100)\end{array}$ & $\begin{array}{l}1.2288^{* * * *} \\
(0.013)\end{array}$ & $\begin{array}{l}1.2386^{* * *} \\
(0.017)\end{array}$ \\
\hline CONG KNOWLEDGE & $\begin{array}{l}0.4121^{\text {**** }} \\
(0.123)\end{array}$ & $\begin{array}{l}1.0708^{* * *} \\
(0.014)\end{array}$ & $\begin{array}{l}0.9996 \\
(0.017)\end{array}$ \\
\hline TEAM SIZE & $\begin{array}{l}0.2231 * * * \\
(0.038)\end{array}$ & $\begin{array}{l}1.0932^{* * * *} \\
(0.002)\end{array}$ & $\begin{array}{l}1.0740^{* * *} \\
(0.003)\end{array}$ \\
\hline AGE & $\begin{array}{l}-0.0223^{* * * *} \\
(0.005)\end{array}$ & $\begin{array}{l}0.9890^{* * * *} \\
(0.001)\end{array}$ & $\begin{array}{l}0.9881^{* * *} \\
(0.001)\end{array}$ \\
\hline FEMALE & $\begin{array}{l}-0.2129 * \\
(0.114)\end{array}$ & $\begin{array}{l}0.9150^{* * * *} \\
(0.012)\end{array}$ & $\begin{array}{l}0.8769 * * * \\
(0.015)\end{array}$ \\
\hline H INDEX ORIGIN & $\begin{array}{l}1.1410^{* * * *} \\
(0.216)\end{array}$ & $\begin{array}{l}1.3172^{* * * *} \\
(0.031)\end{array}$ & $\begin{array}{l}1.2930 * * * \\
(0.045)\end{array}$ \\
\hline CONSTANT & $\begin{array}{l}1.7045^{* * *} \\
(0.470)\end{array}$ & $\begin{array}{l}5.5909 * * * \\
(0.357)\end{array}$ & $\begin{array}{l}15.9600^{* * * *} \\
(4.632)\end{array}$ \\
\hline Filed dummies & $\mathrm{Y}$ & $\mathrm{Y}$ & $\mathrm{Y}$ \\
\hline Country dummies & $\mathrm{Y}$ & $\mathrm{Y}$ & $\mathrm{Y}$ \\
\hline Institution & $\mathrm{N}$ & $\mathrm{N}$ & $\mathrm{Y}$ \\
\hline Observations & 4,297 & 4,297 & 2,609 \\
\hline $\mathrm{R}-\mathrm{Sq}$ & 0.1640 & & \\
\hline Pseudo R-Sq & & 0.115 & 0.205 \\
\hline LR Chi-Sq & & $6528.7 * * *$ & $7367.7 * * *$ \\
\hline $\begin{array}{l}\text { F stat } \\
P \text { value of Wald test on } \\
\text { coefficients differences: }\end{array}$ & $27.7 * * *$ & & \\
\hline $\begin{array}{l}\text { POWER MOBILE - } \\
\text { NON POWER } \\
\text { MOBILE }\end{array}$ & 0.000 & 0.000 & 0.000 \\
\hline $\begin{array}{l}\text { POWER MOBILE - } \\
\text { POWER } \\
\text { NONMOBILE }\end{array}$ & 0.000 & 0.000 & 0.000 \\
\hline
\end{tabular}

Notes: Teams grouped according to the decision power of the corresponding author. Dependent variable: IF and 3 year total citations. OLS and Poisson models

Heteroskedasticty robust standard errors. Significance level: *** 99\%; ** 95\%; *90\%.

backward citations across subfields (GINI Index, Simpson Index, ratio of citations to subfields other than those of the journal in which the focal paper has appeared) that are meant to proxy the level of multidisciplinarity of the contents of the focal paper. Wang et al. (2015) provide a detailed discussion of these indicators. 
Second, for comparison purposes, we use the method developed by Uzzi and colleagues (2013) to assess the degree of 'atypicality' of research articles. The method calculates the commonness score for an article's referenced journal pairs, where commonness is computed as a $z$-score, (i.e., the number of observed co-citations between the pair the number of expected co-citations/standard deviation of the co-citations). We have obtained the atypicality indicator measure for each of our focal papers. ${ }^{[18]}$

We have then analysed the correlation patterns between the self-reported measure of creativity and the bibliometric indicators for our focal papers.

We test our measure of creative intent with both univariate and multivariate approaches. Results are presented in Tables IX and X. In Table IX we present simple t-tests comparing the distribution of the bibliometric indicators for the subgroups of publications based on the dichotomous variable CREATIVE used in the previous econometric models. In Table $\mathrm{X}$ we show the results of a logit model in which we use among covariates both the bibliometric indicators and a set of controls. Overall, results indicate the presence of significant correlation patterns between the dummy variable GREATIVE and the bibliometric proxies for multidisciplinarity and atypicality. In particular, focal papers classified as highly creative tend to have backward citations that are spread more among different subfields, as captured by the variables GINI DISPERSION INDEX and SIMPSON INDEX in Table X. The result is robust to the inclusion of controls for respondent characteristics as well as team size.

Table IX. Robustness

\begin{tabular}{|c|c|c|c|c|}
\hline \multirow{2}{*}{ Bibliometric Measure } & \multicolumn{3}{|c|}{ Atypicality [based on Uzzi et al. (2013)] } & \multirow[b]{2}{*}{ Interval] } \\
\hline & Mean & Std. Err. & [95\% Conf. & \\
\hline NON GREATIVE & 0.0772 & 0.0310 & 0.0163 & 0.1381 \\
\hline CREATIVE & 0.6045 & 0.0369 & 0.5320 & 0.6769 \\
\hline diff & -0.5272 & 0.0488 & -0.6229 & -0.4315 \\
\hline \multirow{2}{*}{ Bibliometric Measure } & \multicolumn{4}{|c|}{ Number of different subfield categories of the journal of the focal paper } \\
\hline & Mean & Std. Err. & {$[95 \%$ Conf. } & Interval] \\
\hline NON GREATIVE & 2.909 & 0.0372 & 2.8365 & 2.9821 \\
\hline CREATIVE & 3.121 & 0.0498 & 3.0237 & 3.2193 \\
\hline diff & -.2118 & 0.0613 & -0.3321 & -0.0915 \\
\hline
\end{tabular}

Simpson Index for the distribution of backward citations across subfields. Higher values

Bibliometric Measure are associated with more dispersed patterns of citations across subfields.

\begin{tabular}{lrrrr} 
& \multicolumn{1}{c}{ Mean } & Std. Err. & [95\% Conf. & \multicolumn{1}{c}{ Interval] } \\
\hline NON CREATIVE & 0.8620 & 0.00208 & 0.8579 & 0.8661 \\
CREATIVE & 0.8868 & 0.00230 & 0.8822 & 0.8913 \\
diff & -0.0247 & 0.00319 & -0.0310 & -0.0185
\end{tabular}

Data for atypicality measure sourced from Thompson Reuters Web of Knowledge Core Collection. 


\begin{tabular}{lccc}
\hline Model & $I$ & $I I$ & $I I I$ \\
\hline ATYPICALITY INDEX & $0.2379^{* * *}$ & & \\
& $(0.023)$ & 0.0369 & $0.1352^{* * * *}$ \\
NUM OWN CATEGORIES & & $(0.030)$ & $(0.035)$ \\
SIMPSON INDEX & & $4.9586^{* * * *}$ & \\
& & $(0.753)$ & $1.0989^{* * *}$ \\
GINI DISPERSION INDEX & & & $(0.482)$ \\
& & & $0.1168^{* * *}$ \\
TEAM SIZE & $0.0836^{* * *}$ & $0.0779^{* * * *}$ & $(0.026)$ \\
& $(0.016)$ & $(0.023)$ & $-0.0135^{* *}$ \\
AGE & 0.0002 & -0.0044 & $(0.005)$ \\
& $(0.003)$ & $(0.004)$ & 0.0163 \\
FEMALE & $-0.1582^{* *}$ & -0.0808 & $(0.130)$ \\
CONST & $(0.080)$ & $(0.109)$ & $-2.2789^{* * *}$ \\
& $-0.8037^{* *}$ & $-5.4105^{* * *}$ & $(0.728)$ \\
Country Dummy & $(0.397)$ & $(0.895)$ & $\mathrm{Y}$ \\
Field Dummy & $\mathrm{Y}$ & $\mathrm{Y}$ & $\mathrm{Y}$ \\
Observations & $\mathrm{Y}$ & $\mathrm{Y}$ & 2,068 \\
Adj. R-sq & 4,297 & 2,068 & 0.0420 \\
& 0.043 & 0.043 & \\
\hline
\end{tabular}

Notes: Validation of the creativity variable through bibliomteric indicators. Dependent variable dummy CREATIVE. Subsamples of focal papers with bibliometric indicators. Logit models.

Significance level: *** 99\%; ** 95\%; *90\%.

Data for atypicality measure sourced from Thompson Reuters Web of Knowledge Core Collection.

As a further robustness check of the creative intent models we have also run the models presented in the section 'Model Design and Results' using the specific survey questions on the degree of creativity and of multidisciplinarity of the focal paper separately, rather than combining them into one single variable, with thresholds set at both 4 and 4.5. Results are not affected.

Decision power. In the models presented in section 4.3 we find a superior performance of those mobile-scientist teams whose corresponding authors have decision power. We interpret this to be evidence of the opportunity that mobile individuals have to make use of their knowledge and carry-out the process of recombination when they have the decision power typical of a principal investigator. An alternative interpretation might relate to assets that are available for research. Indeed, it might be the case that the recruitment of a foreign scientist in a leading position indicates the availability of resources dedicated to the related research line. Such a situation would generate spurious correlations between our variable of decision power of the mobile scientist and the team performance. ${ }^{[19]}$

The optimal way to control for this effect would be to have some direct measure of the resources available to each team for conducting the research activities. 
Unfortunately, we do not have data on funding for the research projects on which the focal papers are based. However, we can exploit additional information from the survey. For each mobile respondent we have data about the reasons behind the decision to move. Among such reasons, we have a specific item for the 'greater availability of research funds' at the destination institution. In the following analyses we exploit this information by focusing on the sub-sample of mobile respondents, performing two tests. First, we compare the importance of 'research funding at the destination institution' as a reason to move between mobile scientists with and without decision power. Second, we run the same model specification of Table $\mathrm{V}$, but control for the variable FUND_RELEVANGE (based on the 1-5 scale answer to the survey question on the importance of 'greater availability of research funds' at the destination institution) and the dummy HIGH_FUND that takes the value of one when FUND_RELEVANCE > 4. Note that in this case we are running the model on the subsample of mobile-scientists.

Results suggest that there is no significant positive association in our data between the decision power positions of mobile scientists and the importance attributed to the availability of research funds as a reason to move (Table XI). Moreover, and more importantly, the performance premium for decision power positions among mobile researchers is still present after controlling for the importance of funding as a reason to move (Table XII).

Sample restrictions, thresholds and model specifications and time window. We run additional robustness checks on the model specifications presented.

First, we run a new model specification in which rather than using split variables (i.e., dividing our teams into 4 mutually exclusive groups according to a specific context factors and the mobility status) we jointly insert interactions among the dummy variable for the mobility status and the dummies related to the three context factors. Estimates based on Poisson models on total citations indicate a positive effect of the interaction dummies confirming the results reported in the current version of the paper. ${ }^{[20]}$

Second, we analyse the sensitivity of results to the threshold used to generate the dummy variable CONG KNOWLEDGE that identifies geographically concentrated subfields. We used a more restrictive threshold at the top 10 per cent instead of at the top 25 per cent, obtaining similar results. For the CREATIVE variable we use as an alternative cut-off the value 4.5 instead of 4 . Again, results are not affected.

Table XI. Robustness control

\begin{tabular}{lcclr}
\hline Group & Mean & Std. Err. & {$[95 \%$ Conf. } & Interval] \\
\hline NON POWER & 3.972 & 0.053 & 3.866 & 4.077 \\
POWER & 3.869 & 0.038 & 3.794 & 3.944 \\
Diff & 0.102 & 0.068 & -0.031 & 0.235 \\
& & & & \\
\hline
\end{tabular}

Notes: Importance of research funds at the destination institution for the migration decision (1-5 scale). Comparison of subgroups of respondents with and without decision power. Subsample of mobile respondents. 
Table XII. Robustness control

\begin{tabular}{|c|c|c|}
\hline MODELS & $I$ & $I I$ \\
\hline \multirow[t]{2}{*}{ DEP VAR } & Citations & Citations \\
\hline & Poisson (irr reported) & Poisson (irr reported) \\
\hline \multirow[t]{2}{*}{ POWER } & $1.1522 * * *$ & $1.1258 * * *$ \\
\hline & $(0.025)$ & $(0.027)$ \\
\hline \multirow[t]{2}{*}{ HIGH FUND } & 1.0047 & \\
\hline & $(0.018)$ & \\
\hline \multirow[t]{2}{*}{ FUND_RELEVANCE } & & $0.9730 * * *$ \\
\hline & & $(0.009)$ \\
\hline \multirow[t]{2}{*}{ CREATIVE } & $1.2479 * * *$ & $1.2450 * * *$ \\
\hline & $(0.022)$ & $(0.023)$ \\
\hline \multirow[t]{2}{*}{ CONG KNOWLEDGE } & $1.1958 * * *$ & $1.1747 * * *$ \\
\hline & $(0.025)$ & $(0.026)$ \\
\hline \multirow[t]{2}{*}{ TEAM SIZE } & $1.1107 * * *$ & $1.1126^{* * *}$ \\
\hline & $(0.004)$ & $(0.004)$ \\
\hline \multirow[t]{2}{*}{ AGE } & $0.9911 * * *$ & $0.9919 * * *$ \\
\hline & $(0.001)$ & $(0.001)$ \\
\hline \multirow[t]{2}{*}{ FEMALE } & $0.8418 * * *$ & $0.8296^{* * *}$ \\
\hline & $(0.018)$ & $(0.020)$ \\
\hline \multirow[t]{2}{*}{ H INDEX ORIGIN } & $1.2229 * * *$ & $1.2131 * * *$ \\
\hline & $(0.044)$ & $(0.048)$ \\
\hline \multirow[t]{2}{*}{ CONSTANT } & $7.5000 * * *$ & $8.3296 * * *$ \\
\hline & $(0.770)$ & $(0.919)$ \\
\hline Filed dummies & $\mathrm{Y}$ & $\mathrm{Y}$ \\
\hline Country dummies & $\mathrm{Y}$ & $\mathrm{Y}$ \\
\hline Observations & 1,322 & 1,322 \\
\hline Pseudo R-Sq & 0.1193 & 0.1168 \\
\hline LR Chi-Sq & $2548.7 * * *$ & $2096.19 * * *$ \\
\hline
\end{tabular}

Notes: Funding and performance of the mobile-scientist teams. Sample restricted to teams with a mobile corresponding author. Poisson model.

Significance level: *** $99 \%$; * 95\%; *90\%.

A further robustness check concerns the dependent variable total citations. In this case, we tested the robustness of the findings to the adoption of a longer time window for forward citations. In particular, we use forward citations received by the focal paper during 6 years, instead of the 3-year period used in prior analyses. ${ }^{[21]}$ The 6 -year total citations variable has a higher mean 24.26 (std dev: 37.65; median: 14; min: 0 max: 983) compared to the 3-year citations variable, reflecting that citations can only accumulate over time. We re-run all models and related specifications using 6 -year citations as the dependent variable (Table XIII). As in previous sections, we report incidence rate ratios rather than coefficients. We run tests of equality of coefficients for the split variables similar to those reported in the previous models. We can reject equality at 99 per cent confidence level in all cases. Interestingly, the use of longer-term citations does not alter the effects and significance of the mobility variable. Moreover, we also find consistent results for the context factors. 
Table XIII. Robustness control

\begin{tabular}{|c|c|c|c|c|}
\hline Model & $I$ & II & III & IV \\
\hline DEP VAR & $\begin{array}{l}6 \text { year } \\
\text { Citations }\end{array}$ & $\begin{array}{l}6 \text { year } \\
\text { Citations }\end{array}$ & $\begin{array}{l}6 \text { year } \\
\text { Citations }\end{array}$ & $\begin{array}{l}6 \text { year } \\
\text { Citations }\end{array}$ \\
\hline MOBILE-SCIENTIST TEAM & $\begin{array}{l}1.4493^{* * * *} \\
(0.094)\end{array}$ & & & \\
\hline POWER MOBILE & & $\begin{array}{l}1.7101 * * * \\
(0.023)\end{array}$ & & \\
\hline NON POWER MOBILE & & $\begin{array}{l}1.3259 \text { *** } \\
(0.019)\end{array}$ & & \\
\hline POWER NON-MOBILE & & $\begin{array}{l}1.1340^{* * * *} \\
(0.012)\end{array}$ & & \\
\hline CREATIVE MOBILE & & & $\begin{array}{l}1.8589 * * * \\
(0.023)\end{array}$ & \\
\hline NON CREATIVE MOBILE & & & $\begin{array}{l}1.3990^{* * * *} \\
(0.017)\end{array}$ & \\
\hline GREATIVE NON-MOBILE & & & $\begin{array}{l}1.2294^{* * * *} \\
(0.010)\end{array}$ & \\
\hline CONG KNOWLEDGE MOBILE & & & & $\begin{array}{l}1.6741^{* * * *} \\
(0.022)\end{array}$ \\
\hline NON CONG KNOWLEDGE MOBILE & & & & $\begin{array}{l}1.3300^{* * * *} \\
(0.015)\end{array}$ \\
\hline CONC KNOWLEDGE NON-MOBILE & & & & $\begin{array}{l}0.9696 \text { *** } \\
(0.009)\end{array}$ \\
\hline CREATIVE & $\begin{array}{l}1.2643^{* * * *} \\
(0.059)\end{array}$ & $\begin{array}{l}1.2648^{* * * *} \\
(0.008)\end{array}$ & & $\begin{array}{l}1.2660^{\text {**** }} \\
(0.008)\end{array}$ \\
\hline CONC KNOWLEDGE & $\begin{array}{l}1.0816 \\
(0.061)\end{array}$ & $\begin{array}{l}1.0794^{* * * *} \\
(0.008)\end{array}$ & $\begin{array}{l}1.0838^{* * * *} \\
(0.008)\end{array}$ & \\
\hline POWER & $\begin{array}{l}1.1982 * * * * \\
(0.067)\end{array}$ & & $\begin{array}{l}1.1896^{* * * *} \\
(0.010)\end{array}$ & $\begin{array}{l}1.1954^{* * * *} \\
(0.010)\end{array}$ \\
\hline TEAM SIZE & $\begin{array}{l}1.0924^{* * * *} \\
(0.010)\end{array}$ & $\begin{array}{l}1.0919 \text { *** } \\
(0.001)\end{array}$ & $\begin{array}{l}1.0921^{\text {***** }} \\
(0.001)\end{array}$ & $\begin{array}{l}1.0922^{* * * *} \\
(0.001)\end{array}$ \\
\hline AGE & $\begin{array}{l}0.9870^{* * * *} \\
(0.002)\end{array}$ & $\begin{array}{l}0.9870 * * * \\
(0.000)\end{array}$ & $\begin{array}{l}0.9869 * * * * \\
(0.000)\end{array}$ & $\begin{array}{l}0.9870^{* * * *} \\
(0.000)\end{array}$ \\
\hline FEMALE & $\begin{array}{l}0.9568 \\
(0.051)\end{array}$ & $\begin{array}{l}0.9573^{\text {**** }} \\
(0.007)\end{array}$ & $\begin{array}{l}0.9607^{* * * *} \\
(0.007)\end{array}$ & $\begin{array}{l}0.9580^{\text {*** }} \\
(0.007)\end{array}$ \\
\hline H INDEX ORIGIN & $\begin{array}{l}1.3218^{* * * *} \\
(0.119)\end{array}$ & $\begin{array}{l}1.3354^{* * * *} \\
(0.019)\end{array}$ & $\begin{array}{l}1.3254 * * * \\
(0.019)\end{array}$ & $\begin{array}{l}1.3339 * * * \\
(0.019)\end{array}$ \\
\hline CONSTANT & $\begin{array}{l}15.5584 * * * \\
(2.571)\end{array}$ & $\begin{array}{l}16.1946^{* * * *} \\
(0.632)\end{array}$ & $\begin{array}{l}15.7322 * * * * \\
(0.623)\end{array}$ & $\begin{array}{l}16.3829^{* * * *} \\
(0.638)\end{array}$ \\
\hline Filed dummies & $\mathrm{Y}$ & $\mathrm{Y}$ & $\mathrm{Y}$ & $\mathrm{Y}$ \\
\hline Country dummies & $\mathrm{Y}$ & $\mathrm{Y}$ & $\mathrm{Y}$ & $\mathrm{Y}$ \\
\hline Observations & 4,297 & 4,297 & 4,151 & 4,297 \\
\hline LR chi2 & $376.3^{* * *}$ & $17145.2^{* * *}$ & $16618.5^{* * * *}$ & $17437.6^{* * *}$ \\
\hline Pseudo R2 & 0.1198 & 0.1202 & 0.1199 & 0.1224 \\
\hline
\end{tabular}

Notes: Dependent variable: total 6-year citations. Baseline and context factors. Poisson models. Incidence rate ratios reported.

Incidence rate ratio reported. Heteroskedasticty robust standard errors.

Significance level: *** 99\%;** 95\%;* 90\%. 


\section{DISGUSSION AND GONGLUSIONS}

In this paper, we have investigated context factors associated with the positive performance premium observed for internationally mobile scientist teams. Our research hypotheses are rooted in the literature of knowledge recombination (Fleming, 2001; Hargadon, 1998; Hargadon and Sutton, 1997; Kogut and Zander, 1992) and learning by hiring (Kogut and Zander, 1992; Mawdsley and Somaya, 2016; Palomeras and Melero, 2010; Rosenkopf and Almeida, 2003; Singh and Agrawal, 2011; Slavova et al., 2016; Song et al., 2003; Tzabbar, 2009). We expand prior knowledge in three ways: by focusing on international (rather than inter-firm) mobility, by looking at the performance (rather than at knowledge flows) of the teams where internationally mobile workers go and by focusing on context factors that moderate the relationship between international mobility and team performance.

The empirical investigation builds on an original dataset of over four thousand research units located in 16 countries. The estimates point to the importance of three context factors that reinforce the positive correlation between having an internationally mobile person on a team and the performance of the team.

First, internationally mobile workers are more likely to be positively associated with performance when the relevant knowledge is more geographically concentrated in specific locations and countries, as opposed to when it is widespread. Because knowledge tends to remain geographically constrained when it is difficult to codify, or when other agglomeration forces are strong, individuals that move from one location to another are more likely to be a plus in these circumstances. Second, internationally mobile workers are more likely to be positively associated with performance when they are associated with activities that involve a high creative intent and likely require extensive knowledge recombination, such as when research themes are highly creative or multidisciplinary. Third, internationally mobile workers are more likely to be positively associated with performance when they work in positions that involve decision power which enable them to draw on the array of new ideas, experiences, mental models and routines brought with them when they move.

The paper has limitations that call for further investigations in future research. A first set of limitations concerns the sample and data. In this paper, we choose to exclude episodes of return mobility, i.e., teams whose corresponding author is an individual working in the country of origin, but who has previously worked abroad. We did so to minimize the incidence of potential confounds associated with positive and negative selection into returning (Borjas and Bratsberg, 1996). However, return migration is acquiring relevance in the global context of growing brain circulation and it is a rather under-investigated issue in the literature. We hope that future research will address this interesting yet underexplored issue.

We also exclude from the sample non co-located teams and teams that span country borders. The choice again is motivated by a desire to reduce the incidence of confounding factors. However, this limitation of our study invites future analyses that investigate the simultaneous interplay of internationally-mobile individuals and external collaborations.

Our sample does not allow us to analyse the specific timing of mobility and how timing affects performance. Although the capability to recombine has been found to be long-lived and to imprint the team work for a considerable time (Joshi and Knight, 2014), it is possible that part of the boost associated with mobility fades over time. 
In this paper, we exploit the richness of a large survey that coded the mobility status of one member for each team, i.e. the corresponding author. A shortcoming of the survey is that it does not provide information concerning the international mobility of all team members in the sense that non-mobile teams could be misclassified if the mobile person on the team were not surveyed. This is clearly a limitation of our study. However, such misclassification would tend to go against our results that find a positive performance premium for mobility, strengthening the inference that there is indeed a positive effect of mobility. ${ }^{[22]}$

A second set of limitations of this work concerns endogeneity. We have provided evidence of correlations between international mobility and team performance. However, in and of themselves, these correlations do not imply causality. A first endogeneity problem relates to selection. Highly qualified individuals who move across borders have a tendency to be high achievers compared to non-mobile individuals (Borjas, 1994). It is therefore possible that the superior performance of mobile-scientist teams is in part explained by the high quality of the internationally mobile team member that we report (Borjas, 1994; Franzoni et al., 2014). The relevance of our findings, however, is only marginally affected by this endogeneity issue, given that our focus was not to show that mobile-scientist teams outperform non-mobile-scientist teams. Rather, our focus was to investigate whether the three context factors (knowledge concentration, creative intent and decision power) further increase the positive association found between mobilescientist teams and performance. In other words, to investigate if even among teams having mobile individuals further premiums exist under specific context factors.

A second and more severe endogeneity concern relates to reverse-causality with regard to the context factors, for example, by management strategies set in place by institutions. Our hypotheses suggest that it is the choice of context that makes the mobile individuals more productive. However, we cannot exclude that the opposite is true, i.e. that mobile individuals are more likely to be hired within specific contexts. For example, some institutions may be more prone to recruit internationally mobile scholars because they can provide them with the ideal settings to exploit their knowledge. To address this concern, albeit only partially, we have run models that include institutional fixed effects to control for differentials in the attractiveness of the institutions and in recruiting strategies. We are aware that this approach is only a first step towards addressing the problem and that further analyses are needed to fully address this caveat.

Despite these limitations, our findings have a series of potentially important implications for practitioners. First, our results suggest that the hiring of internationally mobile workers is not always equally fruitful. This suggests that companies need to place special focus on creating conditions that facilitate capturing the potential richness of knowledge, ideas, expertize, and routines that international workers could supply. Our results also suggest three specific areas of attention that likely make a difference for gaining the performance premium. In general, international hires are more important in those cases in which companies need access to highly specialized knowledge, such as cutting-edge technologies. It is also more important whenever the relevant knowledge does not exist locally or excellence centres are located away from the company country. In these cases, international hiring can be the most effective and timely way for acquiring the relevant knowledge, which cannot be acquired by hiring individuals trained in the same-country or by internal training or even by remote collaborations. 
A further implication is that international hiring, in and of itself, does not guarantee knowledge use, nor performance premiums. Instead, it is the activities that the mobile worker is called on to perform that create the conditions and opportunities for using and recombining knowledge brought by the international worker with that of local knowledge. This implies that international hiring is more relevant for positions where workers are involved in creative activities, such as new product development, new market search or corporate entrepreneurship. Conversely, international hiring would be less of a plus if it targets filling positions which involve routine activities or filling positions where innovation is expected to happen along incremental or predictable trajectories. Furthermore, our results suggest that the knowledge recombination potential brought in by internationally mobile individuals can be better exploited if companies hire international talent for positions that entail high decision power and involve frequent exchange and coordination with other team members. This suggests that international hiring may be more beneficial if directed at managerial positions as opposed to lower-level positions.

In conclusion, we believe that the paper provides important insights into context factors that allow companies to maximize the gains of international hiring. Future analysis is called for to expand research on other context factors and to sharpen the veracity of our results.

\section{ACKNOWLEDGMENT}

We are indebted to ECOOM, KU Leuven, Belgium for providing data sourced from Thompson Reuters Web of Knowledge Core Collection. We thank Professor Wolfang Glanzel, Director of ECOOM, for kindly providing the indicators of atypicality for the focal papers and Dr. Jian Wang, of ECOOM, for computing the measures. We thank Cristina Rossi-Lamastra, Paola Rovelli and Annalisa Croce for useful comments.

\section{NOTES}

[1] India, China and the Philippines account for one-fifth of all the international mobility of the tertiaryeducated (79).

[2] 'The eternal apprentice', Time Magazine, 8 November 1948, vol. 52, p. 81.

[3] E.g., absence of non-competing agreements that would condition the reuse of the mobile worker's knowledge (79).

[4] The GlobSci data release has been supported by the National Bureau of Economic Research, USA. Related data are made available on the NBER website. Data source: http://www.nber.org/workinggroups/ipe/ipe_researchproject.html.

[5] The records that did not report email address for corresponding author were 0.9 per cent in biology, 3.6 per cent in chemistry, 2.9 per cent in earth and environmental sciences and 4.5 per cent in materials science.

[6] Australia, Belgium, Brazil, Canada, Denmark, France, Germany, India, Italy, Japan, Netherlands, Spain, Sweden, Switzerland, the UK, and the USA. For the USA, we kept the .edu addresses.

[7] The survey was translated in seven languages and respondents were allowed to switch language on the platform.

[8] Scimago Journal and Country Rank. Retrieved from http://www.scimagojr.com in June 2015.

[9] The wording used in the related questions in the survey are the following: Q1: 'With regard to the area of research, this paper is in a highly creative area of research' Q2: 'With regard to the area of research, this paper is in an interdisciplinary area of research' (1: strongly disagree; 5 : strongly agree). For a description of the questionnaire and for accessing the raw data see: http://www.nber.org/workinggroups/ipe/ipe_researchproject.html.

[10] The combined variable is distributed as follows. Mean: 3.52; Std dev: 0.850; min: 1 max: 5. The scale reliability coefficient is 0.774 . As a robustness check we also run models using the two original survey variables separately and thresholds equal to 4 or 4.5 for the generation of related dummy variables. See 'Robustness Checks' section below for details. 
[11] A country has an Hirsch index equal to $\mathrm{K}$ if at least $\mathrm{K}$ papers among those carried out during a certain time period by scientists located in the country have received at least $\mathrm{k}$ citations each.

[12] ScimagoJournal and Country Rank. Retrieved from http://www.scimagojr.com on 18 April 2012.

[13] The check was performed with the estat vif routine of Stata 14, using centered factors. Across the various models estimates, the covariate MOBILE-SCIENTIST TEAM has a maximum VIF of 2.68 and the VIF range for the other covariates excluding country dummies is 1.04-3.36.

[14] We thank an anonymous reviewer for suggesting the relevance of this control.

[15] We opted for including only institutions with at least 5 observations. This led to a reduction of about 40 per cent in the number of usable observations.

[16] In Poisson models Incidence Rate Ratios (IRR) are computed by exponentiating coefficients. Hence, reported values of IRR larger than one imply a positive impact of the covariate on the dependent variable. In particular, the estimated IRR is the rate ratio in the dependent variable for a one-unit increase in the covariate, given the other variables are held constant in the model.

[17] In particular we used a top 10 per cent threshold on the distribution of the HHI index instead of the top 25 per cent.

[18] The measure was computed at ECOOM, KU Leuven, Belgium; data sourced from Thompson Reuters Web of Knowledge Core Collection. We thank Professor Wolfang Glänzel, Director of ECOOM, for kindly providing the indicators of atypicality for the focal papers and and Dr. Jian Wang, of ECOOM, for computing the measures.

[19] We thank an anonymous reviewer for raising this relevant issue.

[20] For the sake of brevity related tables are not reported but are available upon request from the authors.

[21] The updated citations have been collected through the Web of Science website in June 2016. We thank an anonymous reviewer for suggesting the importance of this robustness check.

[22] We acknowledge the useful suggestion of an anonymous reviewer on this point.

\section{APPENDIX}

Table AI. Correlation matrix. Pairwise correlation coefficients

\begin{tabular}{|c|c|c|c|c|c|c|c|c|c|c|}
\hline & & 1 & 2 & 3 & 4 & 5 & 6 & 7 & 8 & 9 \\
\hline$\underline{1}$ & $\begin{array}{l}\text { IMPACT } \\
\text { FACTOR }\end{array}$ & 1.0000 & & & & & & & & \\
\hline$\underline{2}$ & $\begin{array}{l}\text { TOTAL } 3 \\
\text { YEARS } \\
\text { CITATIONS }\end{array}$ & 0.5339 & 1.0000 & & & & & & & \\
\hline$\underline{3}$ & $\begin{array}{l}\text { MOBILE- } \\
\text { SCIENTIST } \\
\text { TEAM }\end{array}$ & 0.0826 & 0.1255 & 1.0000 & & & & & & \\
\hline 4 & POWER & 0.0866 & 0.0345 & -0.0746 & 1.0000 & & & & & \\
\hline$\overline{\mathbf{5}}$ & CREATIVE & 0.1114 & 0.0915 & 0.0844 & 0.0426 & 1.0000 & & & & \\
\hline$\overline{\mathbf{6}}$ & $\begin{array}{l}\text { CONC } \\
\text { KNOWLEDGE }\end{array}$ & 0.1451 & 0.0855 & 0.0415 & 0.0454 & 0.0089 & 1.0000 & & & \\
\hline 7 & TEAM SIZE & 0.1690 & 0.1785 & -0.0483 & 0.0011 & 0.0780 & 0.1189 & 1.0000 & & \\
\hline$\overline{8}$ & AGE & 0.0225 & -0.0285 & -0.0645 & 0.4605 & 0.0147 & 0.0521 & 0.0506 & 1.0000 & \\
\hline$\overline{\mathbf{9}}$ & FEMALE & -0.0287 & -0.0208 & -0.0454 & -0.1608 & -0.0374 & 0.0574 & 0.0585 & -0.1428 & 1.0000 \\
\hline$\underline{\mathbf{1 0}}$ & $\begin{array}{l}\text { H INDEX } \\
\text { ORIGIN }\end{array}$ & 0.1540 & 0.0371 & -0.4779 & 0.1720 & -0.0769 & 0.0667 & -0.0334 & 0.1367 & -0.0131 \\
\hline
\end{tabular}




\section{REFERENGES}

Agrawal, A., Cockburn, I. and McHale, J. (2006). 'Gone but not forgotten: Knowledge flows, labor mobility, and enduring social relationships'. Fournal of Economic Geography, 6, 571-91.

Ahuja, G. and Lampert, G. M. (2001). 'Entrepreneurship in the large corporation: A longitudinal study of how established firms create breakthrough inventions'. Strategic Management fournal, 22, 521-43.

Almeida, P. and Kogut, B. (1999). 'Localization of knowledge and the mobility of engineers in regional networks'. Management Science, 45, 905-17.

Argyres, N. and Silverman, B. (2004). 'R\&D, organization structure, and the development of corporate technological knowledge'. Strategic Management Fournal, 25, 929-58.

Azoulay, P., Graff Zivin, J. S. and Wang, J. (2010). 'Superstar extinction'. The Quarterly Fournal of Economics, 125, 549-89.

Black, G. C. and Stephan, P. (2010). 'The economics of university lab science and the role of foreign graduate students and postdoctoral scholars'. In Glotfelter C. T. (Ed.), American Universities in a Global Market. Chicago, IL: University of Chicago Press, 129-62.

Borjas, G. J. (1994). 'The economics of immigration'. Fournal of Economic Literature, 32, 1667-717.

Borjas, G. J. and Bratsberg, B. (1996). 'Who leaves? The outmigration of the foreign-born'. The Review of Economics and Statistics, 78, 165-76.

Breschi, S. and Lissoni, F. (2001). 'Knowledge spillovers and local innovation systems: A critical survey'. Industrial and Corporate Change, 10, 975-1005.

Breschi, S. and Lissoni, F. (2009). 'Mobility of skilled workers and co-invention networks: An anatomy of localized knowledge flows'. Fournal of Economic Geography, 9, 439-68.

Bunderson, S. (2003a). 'Recognizing and utilizing expertise in work groups: A status characteristics perspective'. Administrative Science Quarterly, 48, 557-91.

Bunderson, S. (2003b). 'Team member functional background and involvement in management teams: Direct effects and the moderating role of power centralization'. Academy of Management Fournal, 46, 458-74.

Burt, R. S. (1997). 'The contingent value of social capital'. Administrative Science Quarterly, 42, 339-65.

Cohen, W. M. and Levinthal, D. A. (1990). 'Absorptive capacity: A new perspective on learning and innovation'. Administrative Science Quarterly, 35, 128-52.

Dokko, G. and Rosenkopf, L. (2010). 'Social capital for hire? Mobility of technical professionals and firm influence in wireless standards committees'. Organization Science, 21, 677-95.

Dokko, G., Wilk, S. L. and Rothbard, N. P. (2009). 'Unpacking prior experience: How career history affects job performance'. Organization Science, 20, 51-68.

Finkelstein, S. (1992). 'Power in top management teams: Dimensions, measurement, and validation'. Academy of Management Journal, 35, 505-38.

Fleming, L. (2001). 'Recombinant uncertainty in technological search'. Management Science, 47, 117-32.

Fleming, L. and Sorenson, O. (2004). 'Science as a map in technological search'. Strategic Management Fournal, 25, 909-28.

Franzoni, C., Scellato, G. and Stephan, P. (2012). 'Foreign-born scientists: Mobility patterns for 16 countries'. Nature Biotechnology, 30, 1250-3.

Franzoni, C., Scellato, G. and Stephan, P. (2014). 'The mover's advantage: The superior performance of migrant scientists'. Economics Letters, 122, 879-93.

Freeman, R. B. and Huang, W. (2015). 'Collaborating with people like me: Ethnic coauthorship within the United States'. Fournal of Labor Economics, 33, S289-318.

Ganguli, I. (2015). 'Immigration and ideas: What did Russian Scientists "Bring" to the United States? On JSTOR'. Fournal of Labor Economics, 33, S257-88.

Groysberg, B., Lee, L.-E. and Nanda, A. (2008). 'Can they take it with them? The portability of star knowledge workers' performance'. Management Science, 54, 1213-30.

Gruber, M., Harhoff, D. and Hoisl, K. (2012). 'Knowledge recombination across technological boundaries: Scientists vs. engineers'. Management Science, 59, 837-51.

Haleblian, J. and Finkelstein, S. (1993). 'Top management team size, GEO dominance, and firm performance: The moderating roles of environmental turbulence and discretion'. Academy of Management fournal, 36, 844-63.

Hamori, M. and Koyuncu, B. (2015). 'Experience matters? The impact of prior CEO experience on firm performance'. Human Resource Management, 54, 23-44.

Hargadon, A. B. (1998). 'Firms as knowledge brokers: Lessons in pursuing continuous innovation'. Califormia Management Review, 40, 209-27. 
Hargadon, A. and Sutton, R. I. (1997). 'Technology brokering and innovation in a product development firm'. Administrative Science Quarterly, 42, 716-49.

Herstad, S. J., Sandven, T. and Ebersberger, B. (2015). 'Recruitment, knowledge integration and modes of innovation'. Research Policy, 44, 138-53.

Hsu, D. H. and Lim, K. (2013). 'Knowledge brokering and organizational innovation: Founder imprinting effects'. Organization Science, 25, 1134-53.

Hsu, D. H., Roberts, E. B. and Eesley, C. E. (2007). 'Entrepreneurs from technology-based universities: Evidence from MIT'. Research Policy, 36, 768-88.

Hunt, J. (2011). 'Which immigrants are most innovative and entrepreneurial? Distinctions by entry visa'. Fournal of Labor Economics, 29, 417-57.

Hunter, R. S., Oswald, A. J. and Charlton, B. G. (2009). 'The elite brain drain'. Economic Fournal, 119, F231-51.

Haussler, C. and Sauermann, H. (2014). The Anatomy of Teams: Division of Labor and Allocation of Credit in Collaborative Knowledge Production. SSRN Working Paper. Available at: http://papers.ssrn.com/ abstract $=2434327$ (accessed 11 July 2016).

Ibarra, H. and Andrews, S. B. (1993). 'Power, social influence, and sense making: Effects of network centrality and proximity on employee perceptions'. Administrative Science Quarterly, 38, 277-303.

Jaffe, A. B., Trajtenberg, M. and Henderson, R. (1993). 'Geographic localization of knowledge spillovers as evidenced by patent citations'. The Quarterly Fournal of Economics, 108, 577-98.

Jones, B. F. (2009). 'The burden of knowledge and the "death of the renaissance man": Is innovation getting harder?' The Review of Economic Studies, 76, 283-317.

Joshi, A. and Knight, A. P. (2014). 'Who defers to whom and why? Dual pathways linking demographic differences and dyadic deference to team effectiveness'. Academy of Management Fournal, 58, 59-84.

Katila, R. and Ahuja, G. (2002). 'Something old, something new: A longitudinal study of search behavior and new product introduction'. Academy of Management Fournal, 45, 1183-94.

Kealey, T. and Ricketts, M. (2014). 'Modelling science as a contribution good'. Research Policy, 43, $1014-24$.

Kerr, S. P., Kerr, W. R. and Lincoln, W. F. (2013). Skilled Immigration and the Employment Structures of U.S. Firms. NBER working paper N.19658. Available at: http://www.nber.org/papers/w19658 (accessed 12 July 2016).

Kerr, W. R. (2013). U.S. High-Skilled Immigration, Innovation, and Entrepreneurship: Empirical Approaches and Evidence. NBER Working Paper n. 19377. Available at: http://www.nber.org/papers/w19377 (accessed 12 July 2016).

Kerr, W. R. and Lincoln, W. F. (2010). 'The supply side of innovation: H-1B visa reforms and U.S. Ethnic Invention'. Fournal of Labor Economics, 28, 473-508.

Kogut, B. and Zander, U. (1992). 'Knowledge of the firm, combinative capabilities, and the replication of technology'. Organization Science, 3, 383-97.

Lawson, C., Geuna, A., Fernández-Zubieta, A., Kataishi, R. and Toselli, M. (2015). 'International careers of researchers in biomedical sciences: A comparison of the US and the UK'. In Geuna, A. (Ed.), Global Mobility of Research Scientists. London: Academic Press, Elsevier, 67-104.

Lee, Y.-N., Walsh, J. P. and Wang, J. (2015). 'Creativity in scientific teams: Unpacking novelty and impact'. Research Policy, 44, 684-97.

Liu, X., Wright, M., Filatotchev, I., Dai, O. and Lu, J. (2010). 'Human mobility and international knowledge spillovers: Evidence from high-tech small and medium enterprises in an emerging market'. Strategic Entrepreneurship Fournal, 4, 340-55.

Maliranta, M., Mohnen, P. and Rouvinen, P. (2009). 'Is inter-firm labor mobility a channel of knowledge spillovers? Evidence from a linked employer-employee panel'. Industrial and Corporate Change, 18, $1161-91$.

Marx, M. (2011). 'The firm strikes back: Non-compete agreements and the mobility of technical professionals'. American Sociological Review, 76, 695-712.

Marx, M., Strumsky, D. and Fleming, L. (2009). 'Mobility, skills, and the Michigan non-compete experiment'. Management Science, 55, 875-89.

Mawdsley, J. K. and Somaya, D. (2016). 'Employee mobility and organizational outcomes: An integrative conceptual framework and research agenda'. Fournal of Management, 42, 85-113.

Miguélez, E. and Moreno, R. (2013). 'Research networks and inventors' mobility as drivers of innovation: Evidence from Europe'. Regional Studies, 47, 1668-85.

Nelson, R. R. and Winter, S. G. (1985). An Evolutionary Theory of Economic Change. Cambridge, MA: Harvard University Press. 
Nerkar, A. and Paruchuri, S. (2005). 'Evolution of R\&D capabilities: The role of knowledge networks within a firm'. Management Science, 51, 771-85.

No, Y. and Walsh, J. P. (2010). 'The importance of foreign-born talent for US innovation'. Nature Biotechnology, 28, 289-91.

OECD-UNDESA. (2013). World-Migration-in-Figures.pdf. Available at: http://www.oecd.org/els/mig/ World-Migration-in-Figures.pdf (accessed 1 September 2015).

Palomeras, N. and Melero, E. (2010). 'Markets for inventors: Learning-by-hiring as a driver of mobility'. Management Science, 56, 881-95.

Polanyi, M. (1962). Personal Knowledge: Towards a Post-Critical Philosophy. Chicago, IL: University of Chicago Press.

Radner, R. (1992). 'Hierarchy: The economics of managing'. Fournal of Economic Literature, 30, 1382-415.

Rosenkopf, L. and Almeida, P. (2003). 'Overcoming local search through alliances and mobility'. Management Science, 49, 751-66.

Rosenkopf, L. and Nerkar, A. (2001). 'Beyond local search: Boundary-spanning, exploration, and impact in the optical disk industry'. Strategic Management fournal, 22, 287-306.

Scellato, G., Franzoni, G. and Stephan, P. (2015). 'Migrant scientists and international networks'. Research Policy, 44, 108-20.

Schilling, M. A. and Green, E. (2011). 'Recombinant search and breakthrough idea generation: An analysis of high impact papers in the social sciences'. Research Policy, 40, 1321-31.

Shapin, S. (2008). The Scientific Life: A Moral History of a Late Modern Vocation. Chicago, IL: University of Chicago Press.

Singh, J. (2005). 'Collaborative networks as determinants of knowledge diffusion patterns'. Management Science, 51, 756-70.

Singh, J. and Agrawal, A. (2011). 'Recruiting for ideas: How firms exploit the prior inventions of new hires'. Management Science, 57, 129-50.

Slavova, K., Fosfuri, A. and De Castro, J. O. (2016). 'Learning by hiring: The effects of scientists' inbound mobility on research performance in academia'. Organization Science, 27, 72-89.

Song, J., Almeida, P. and Wu, G. (2003). 'Learning-by-hiring: When is mobility more likely to facilitate interfirm knowledge transfer?' Management Science, 49, 351-65.

Stephan, P. E. (1996). 'The economics of science'. Fournal of Economic Literature, 34, 1199-235.

Stephan, P. E. and Levin, S. G. (2001). 'Exceptional contributions to US science by the foreign-born and foreign-educated'. Population Research and Policy Review, 20, 59-79.

Stephan, P. (2012). How Economics Shapes Science. Cambridge, MA: Harvard Business Press.

Stephan, P., Franzoni, C. and Scellato, G. (2016). 'Global competition for scientific talent: Evidence from location decisions of $\mathrm{PhDs}$ and postdocs in 16 countries'. Industrial and Corporate Change, 25, 457-85.

Strumsky, D. and Lobo, J. (2015). 'Identifying the sources of technological novelty in the process of invention'. Research Policy, 44, 1445-61.

Stuart, T. E. and Podolny, J. M. (1996). 'Local search and the evolution of technological capabilities'. Strategic Management Fournal, 17, 21-38.

Turner, K. L. and Makhija, M. V. (2012). 'The role of individuals in the information processing perspective'. Strategic Management Fournal, 33, 661-80.

Tzabbar, D. (2009). 'When does scientist recruitment affect technological repositioning?' Academy of Management fournal, 52, 873-96.

Uzzi, B., Mukherjee, S., Stringer, M. and Jones, B. (2013). 'Atypical combinations and scientific impact'. Science, 342, 468-72.

Verhoeven, D., Bakker, J. and Veugelers, R. (2016). 'Measuring technological novelty with patent-based indicators'. Research Policy, 45, 707-23.

Volberda, H. W., Foss, N. J. and Lyles, M. A. (2010). 'Absorbing the concept of absorptive capacity: How to realize its potential in the organization field'. Organization Science, 21, 931-51.

Wang, J., Thijs, B. and Glänzel, W. (2015). 'Interdisciplinarity and impact: Distinct effects of variety, balance, and disparity'. PLoS One, 10, 1-7.

Wang, J., Veugelers, R. and Stephan, P. (2016). Bias Against Novelty in Science: A Cautionary Tale for Users of Bibliometric Indicators. NBER Working paper series n. 22180. Available at: http://www.nber.org/ papers/w22180.pdf (accessed 30 June 2016). 